\title{
A Meta-Analysis Investigating the Association Between Metacognition and Math Performance in Adolescence
}

\author{
Gemma Muncer $^{1}$ (D) Philip A. Higham ${ }^{2}$ - Corentin J. Gosling ${ }^{3,4}$. \\ Samuele Cortese $e^{5,6,7,8,9} \cdot$ Henry Wood-Downie ${ }^{5,10}$ - Julie A. Hadwin ${ }^{11}$
}

Accepted: 21 May 2021 / Published online: 3 July 2021

(C) The Author(s) 2021

\begin{abstract}
Poor math and numeracy skills are associated with a range of adverse outcomes, including reduced employability and poorer physical and mental health. Research has increasingly focused on understanding factors associated with the improvement of math skills in school. This systematic literature review and meta-analysis investigated the association between metacognition and math performance in adolescence (11-16-yearolds). A systematic search of electronic databases and grey literature (to 04.01.2020) highlighted 31 studies. The quantitative synthesis of 74 effect sizes from 29 of these studies (30 independent populations) indicated a significantly positive correlation between metacognition and math performance in adolescence $(r=.37,95 \% \mathrm{CI}=[.29, .44]$, $p<.001)$. There was significant heterogeneity between studies. Consideration of online (versus offline) measures of metacognition and more complex (versus simple) measures of math performance, and their combination, was associated with larger effect sizes; however, heterogeneity remained high for all analyses.
\end{abstract}

Keywords Adolescence $\cdot$ Metacognition $\cdot$ Math

Math and numeracy skills (the ability to use numbers and solve mathematical problems in everyday life; National Numeracy 2020) are often used in daily tasks, including managing money and finances, using travel timetables, or following a recipe (Price and Ansari 2013). Studies have highlighted the societal implications of numeracy skills. For example, Martin et al. (2014) estimated the cost of poor numeracy to the UK economy to be $£ 20.2$ billion per year in 2012 (approximately 1.3\% of Gross Domestic Product). Further studies have found that

This work formed part of a doctoral degree in educational psychology awarded to the first author and was carried out in the Centre for Innovation in Mental Health - Developmental Lab, School of Psychology, University of Southampton, Southampton, SO17 1BJ.

Gemma Muncer

gcs1n17@southamptonalumni.ac.uk

Extended author information available on the last page of the article 
low numerical ability in childhood and adolescence was associated with outcomes in adulthood that negatively impacted employability and prospective earnings (Crawford and Cribb 2013; Wolf 2011) and was linked to increased youth offending and criminality (Meltzer et al. 1984; Parsons 2002).

Several initiatives have aimed to develop an international profile of math achievement. For example, the Trends in International Mathematics and Science Study (TIMSS 2019; Mullis et al. 2020) reported that across 64 countries, there was a general increase in math achievement in 9-10- and 13-14-year-old pupils since this US initiative was started in 1995. Further reports have highlighted that most countries require pupils to study math to the age of 16-17 years, where the qualification achieved at this point in education typically represents a critical gateway to further study or training (Hodgen and Pepper 2010). To meet the requirements for progression in the UK context, for example, all pupils are expected to achieve a pass grade in GCSE math at 15-16 years. While a pass is required to access most UK higher education courses and employment, around one-quarter of adolescents do not achieve this level (Ofqual 2019).

Recognising the impact of math on developmental outcome in adolescence and across the lifespan has increasingly focused research agendas on understanding factors associated with achievement in this subject. Mullis et al. (2020) highlighted a complex profile of factors linked to a positive outcome in math, including gender (with males outperforming females in $>90 \%$ of countries), the home context (e.g. books in the home, parent occupation), and the school context (e.g. more school resources, more time spent studying math, a school focus on achievement, fewer pupil behavioural problems). In addition, the report outlined several pupil self-reported factors associated with math achievement, including more enjoyment and value of the subject, as well as increased confidence and metacognitive skill (i.e. pupils' reported awareness of their own ability to solve complex mathematical problems).

\section{Defining Metacognition}

Metacognition (MC) refers to an individual's self-regulation of their own learning, including an awareness of their own strengths and weaknesses, as well as a recognition of the strategies that may be useful to progress in specific tasks (e.g. how well the individual monitors progress during the completion of a task, and the extent to which they recognise what behavioural change is needed to reach an outcome; Credé and Phillips 2011; Hacker et al. 1998). Metacognition is typically divided into two or three parts in the research literature. The dyadic model of MC (Nelson and Narens 1990) includes two components linked to (1) an individual's awareness of their strategic knowledge associated with memory and learning and (2) their ability to monitor (e.g. "How well am I doing?") and flexibly control ("What do I need to do?") cognitive processing as they complete a task. The ternary model divides metacognition into three components (e.g. Efklides 2008). The first two components fit with those proposed in the dyadic model, including knowledge (the extent to which a person is aware of what they know) and cognitive skill (strategy use to monitor and regulate cognition and effort to meet task goals). The third component of MC in the ternary model is proposed to reflect feelings that emerge (e.g. satisfaction and confidence) when an individual engages in a task. This component has been termed "experience" (Flavell 1979, p. 906), and it is linked to the implicit use of cues associated with a student's knowledge and skill as they progress through a task (Dent and Koenka 2016; review by Schneider 2008). 
Researchers have proposed that different aspects of $\mathrm{MC}$ are closely related. If an individual is aware of their own knowledge, then this awareness can increase attentional focus on what is still to be learnt (Metcalfe and Finn 2008) and effectively guide self-directed learning (Garrett et al. 2006; Ohtani and Hisasaka 2018). In addition, monitoring is a necessary pre-requisite to regulate cognitive activity and behavioural response (Baker 1989). In support, several studies have found a positive correlation between MC knowledge and the use of self-regulation MC strategies in learning (e.g. Schraw et al. 2012; Schraw and Dennison 1994).

\section{Measuring Metacognition}

A systematic review with 4-16-year-olds identified 84 MC measures across 149 papers (Gascoine et al. 2017). Measures of MC are typically categorised as online or offline. Offline measures are questionnaires that aim to capture an individual's self-reported perception of their own MC ability based on previous learning experiences (see Saraç and Karakelle 2012). For example, the MC self-regulation subscale in the motivated strategies for learning questionnaire (MSLQ, Pintrich 1991) asks respondents to read 12 statements (e.g. "I ask myself questions to make sure I know the material I have been studying") and to indicate how true each statement is for them. The metacognitive awareness inventory (MAI, Schraw and Dennison 1994) similarly asks individuals to indicate whether each of 52 statements related to learning is true (1 point) or false ( 0 points) for them (e.g. "I try to use strategies that have worked in the past"). The junior metacognitive awareness inventory (Jr. MAI, Sperling et al. 2002) asks children (811 years; 12 items) and adolescents (12-15 years; 18 items) about the frequency of use of metacognitive strategies during learning (e.g. "I think of several ways to solve a problem and then choose the best one"). In contrast, online measures capture an individual's MC via ongoing behaviour and performance as they complete a task (Saraç and Karakelle 2012; Veenman and van Cleef 2019). These include think-aloud protocols, for example, where individuals verbalise their thoughts while engaging in a task. Verbalisations are recorded and later coded for the quality and/or quantity of MC activity (e.g. Veenman et al. 2005).

Recent discussion has focused on the distinction between online and offline measures and particularly whether self-reported MC measures that are relevant to processes in ongoing tasks should be classed as online or offline. These measures include individuals' confidence judgements, accuracy measures (i.e. the difference between an individual's predicted score and actual score; also known as calibration accuracy), and judgement of learning (JOL) scores. JOLs typically ask individuals how confident they are from 0 to $100 \%$ that they would recall learnt information in a later test (e.g. Myers et al. 2020). Saraç and Karakelle (2012) classified confidence judgements and JOLs as online, as they pertain to a specific task at hand. In contrast, Veenman and van Cleef (2019) considered them as offline judgements, as they typically follow (i.e. but sit outside) the completion of a task. More recently, Craig et al. (2020) categorised confidence judgements during a task (where individuals reported their confidence in their answers to specific questions immediately after each item and before completing further items) as online and those made following the completion of an entire task as offline.

Some research has reported poor correspondence between offline and online MC measurements. Sperling et al. (2004) found a significant correlation between undergraduate responses to two offline self-reported questionnaires: the MAI (Schraw and Dennison 1994) and the MC self-regulation scale of the MSLQ (Pintrich 1991). However, both offline questionnaires were 
not linked to the accuracy of students' confidence against their predicted test scorescategorised in this paper as online. An earlier study similarly found no association between scores on the MAI (an offline questionnaire) with 14-17-year-old student judgements about whether they could solve a math question (Tobias et al. 1999). The lack of correspondence between online and offline measures across studies suggests that they may be measuring different facets of MC. Sperling et al. (2002) suggested, for example, that the Jr. MAI is a broad measure of $\mathrm{MC}$, as compared to some existing measures that focus more specifically on MC self-regulation. Saraç and Karakelle (2012) further proposed that online measures may capture implicit experience-based judgements, whereas offline measures may reflect more explicit knowledge-based judgements of MC.

\section{Metacognition and Academic Performance}

Several systematic reviews and meta-analyses have explored associations between MC and academic achievement across different subjects in adult populations, highlighting small but significant associations between offline MC measures and achievement. Credé and Phillips (2011) found that student scores on the MC self-regulation scale of the MSLQ were moderately significantly correlated with grade point average (GPA; 98 correlations from 24 independent samples, $N=9,696, r=.22,90 \% \mathrm{CI}=[.03, .47])$ and current course grade (431 correlations from 53 samples, $N=15,321, r=.23,90 \% \mathrm{CI}=[.02, .45])$. Richardson et al. (2012) considered 50 constructs associated with achievement and identified a small but significant correlation $(r=.18,95 \% \mathrm{CI}=[.10, .26])$ between student MC and GPA $(N=$ 6,205 across 9 studies).

Ohtani and Hisasaka (2018) extended these analyses to synthesise 149 effect sizes from 118 independent samples that included children and adults. The authors similarly identified small and moderate correlations between $\mathrm{MC}$ with academic performance $(r=.28,95 \% \mathrm{CI}=[.24$, $.31])$ and intelligence $(r=.33,95 \% \mathrm{CI}=[.26, .39])$. In an earlier study, Dent and Koenka (2016) also showed a small but significant correlation between MC and academic achievement $(r=.20,95 \% \mathrm{CI}=[.16, .24])$ across 61 studies carried out in North America and Canada with school-aged children and adolescents aged 6-19 years. Both meta-analyses found that online MC (vs. offline) measurements were most clearly associated with achievement. Respective effect sizes for online and offline associations were $r=.53(90 \% \mathrm{CI}=[.45, .61])$ and $r=.23$ $(90 \% \mathrm{CI}=[.20, .26]$; Ohtani and Hisasaka 2018) and $r=.39(95 \% \mathrm{CI}=[.34, .43])$ and $r=.15$ $(95 \% \mathrm{CI}=[.12, .18]$; Dent and Koenka 2016).

Previous research has found that while MC thinking is evident in young children, its use in learning contexts to efficiently plan and control effort and attention to focus on what needs to be learned increases across childhood (Paulus et al. 2014; review by Schneider 2008). In a review of interventions on achievement in primary and secondary school children aged 5-16 years, Dignath and Büttner (2008) reported a large effect size for the impact of self-regulated programmes (including those based on MC strategy) on mathematics and academic achievement more broadly. The review further indicated that secondary (vs. primary) school-aged children and adolescents were most able to benefit from interventions that included the promotion of MC strategies in school.

Meta-analyses have also considered whether associations between MC and achievement were moderated by age. Ohtani and Hisasaka (2018) reported an increased effect size for children relative to adults between MC and achievement across subjects; however, overall age 
(separated into three broad categories including elementary (6-12 years), secondary (13-18), and adults (18 years and above)) did not moderate this association. Dent and Koenka (2016) similarly tested the hypothesis that the association between MC and achievement would increase with age. Comparisons between age were also not significant, and the results showed a small positive effect size across elementary $(r=.24,95 \% \mathrm{CI}=[.15, .32])$, secondary $(r=.21$, $95 \% \mathrm{CI}=[.16, .25])$, and high school students $(r=.18,95 \% \mathrm{CI}=[.10, .25])$. Contrary to expectations, however, a further age analysis indicated a stronger effect size for 5-6-year-olds $(r=.42,95 \% \mathrm{CI}=[.36, .48])$ compared with $8-11$-year-olds $(r=.11,95 \% \mathrm{CI}=[.02, .20])$. The analysis for the younger age group was, however, based on a small number of studies $(n=$ 4) and all had used online MC measures, indicating a conflation of age and measurement in this analysis.

\section{Metacognition and Math Performance}

Several studies have reported an association between $\mathrm{MC}$ and math achievement in children and adolescents (e.g. Özsoy 2011; van der Walt et al. 2008). Consistently, Dent and Koenka (2016) carried out a further analysis in their review that focused on subject-specific associations and reported a small correlation between $\mathrm{MC}$ and math achievement across children and adolescents $(n=39$ studies; $r=.21,95 \% \mathrm{CI}=[.03, .27])$. The effect size of the association was similar to that reported for English and science but significantly smaller compared with social studies $(r=.34,95 \% \mathrm{CI}=[.27, .40])$.

Further research has, however, demonstrated non-significant associations between MC and math achievement (e.g. Maras et al. 2019; Young and Worrell 2018). Some researchers have suggested that the disparity in findings across MC studies may be due to differences in how MC is conceptualised and assessed (Desoete and Roeyers 2006; Veenman et al. 2006). The measurement of MC goes some way to explain differences in findings, with online (vs. offline) measures being most clearly linked to academic achievement (reviews by Dent and Koenka 2016; Ohtani and Hisasaka 2018). The disparity in results between studies may also be a function of how math performance is measured.

Campbell (2005) proposed that mathematical ability is made up of two key elements: numerical ability (basic number representation and simple arithmetic and operations) and mathematical problem-solving (the generation of solutions from abstract representations of mathematical relations in context-rich problems). Other researchers have divided mathematical challenges into routine (i.e. questions that test student knowledge of what was recently covered) and non-routine problems (i.e. those that cannot be solved immediately and often require complex multi-step problem-solving; Mayer 1998). Non-routine problems typically go beyond existing knowledge and skills, requiring the solver to plan, monitor, and review their solution (Mayer 1998; Verschaffel et al. 2010), and these are increasingly integrated into the math curriculum across development (e.g. UK Department for Education 2014). For example, Mokos and Kafoussi (2013) asked 10-year-olds to think aloud when completing open-ended, everyday (authentic), and complex mathematical problems. The results showed that MC control and monitoring were most evident when children were asked to complete complex math problems. In a review of think-aloud methods, Jordano and Touron (2018) also reported that children's use of MC strategy increased with more complex and open-ended mathematical tasks. 


\section{Aims of the Systematic Review}

Based on previous studies and reviews of existing research, there is an emerging consensus that MC plays a small but consistent role in understanding individual differences in achievement across childhood and adolescence. Studies have also demonstrated evidence for a specific association between $\mathrm{MC}$ and math performance. These findings are, however, more mixed and may reflect differences in the way in which researchers have measured MC and achievement in math. In the current paper, we extend existing research to consider the strength of association between MC and math in adolescence. Adolescents are recognised to utilise MC more efficiently (Dermitzaki 2005; Veenman et al. 2006), are faced with increasingly more complex mathematical problems to solve (Department for Education, 2014), and are working towards key examinations (Hodgen and Pepper 2010). It therefore represents a stage of education that is critical for identifying factors that education stakeholders and practitioners can utilise to promote optimal achievement in school for the best outcome of pupils.

Following previous reviews (e.g. Dent and Koenka 2016; Ohtani and Hisasaka 2018), we anticipated that the association with MC and math performance in adolescents would be most evident when MC is measured using online (vs. offline) measures. We extended previous analyses to test the possibility that, across studies, the association between MC and math performance would be stronger for complex (vs. simple) math tasks. We additionally carried out exploratory analyses to consider the combination of MC measure and math assessment and anticipated that associations would be most evident for studies using online measures and more complex math assessments. Furthermore, we provided a comprehensive quality assessment of existing research and broadened the scope and focus of previous systematic reviews and meta-analyses by placing no limit on literature searches with respect to year or language of publication and via the inclusion of a comprehensive quality assessment of existing research.

\section{Method}

This review was carried out following the best practice guidelines for conducting a systematic review published by Siddaway et al. (2019) and the Preferred Reporting Items for Systematic Review and Meta-Analysis guidelines (PRISMA; Moher et al. 2015). The protocol was determined before starting the review, and a title registration was pre-registered with the Campbell Collaboration (review number 19-009).

\section{Search Strategy}

We used variations of the terms metacognition, math, and performance (see Table 1) to search the titles, abstracts, and keywords of records in four databases: Education Resources Information Centre (ERIC; 1966-2019; $n=542)$, Web of Science Core Collection $(1990-2019 ; n=$ 880), and PsycINFO and PsycARTICLES via EBSCO (1887-2019; $n=628)$. Searches were initially conducted up to 15.07.2019 and were repeated on 04.01.2020, following data extraction, to identify papers that had become available since initial searches $(n=28)$. No limiters were imposed on publications (e.g. relating to publication date or language). The syntax was adapted to meet the requirements of each database (see Supplementary Material A for an example search). To include unpublished research, we additionally searched ProQuest Dissertations and Theses Global (using the terms in Table $1 ; n=327$ ) and OpenGrey $(n=11)$. 
Due to input restrictions, the keywords metacogniti* AND math* were used to search OpenGrey. The reference lists of papers included in the final sample were also manually screened for additional potentially relevant studies $(n=93)$. Two researchers independently carried out all database searches and yielded identical results (i.e. 100\% agreement). Pilot searches included three additional terms for MC (resolution, calibration, and self-regulation) which were subsequently removed due to producing a high number of irrelevant papers.

\section{Inclusion and Exclusion Criteria}

The titles and abstracts of all records retrieved via the systematic search $(n=1,985$ after duplicates were removed) were screened against the pre-determined inclusion criteria. Studies were included if (i) the research reported the strength of association between MC and math performance (e.g. by reporting the Pearson correlation coefficient). Where studies investigated the impact of a MC intervention, these were only included if the statistical relationship between MC and math performance was reported before participants took part in the intervention (at baseline) or in a control group, (ii) participants were aged 11-16 ( \pm two years if $\geq 80 \%$ of the sample were aged 11-16), (iii) the study included an objective measure of math performance (e.g. school assessment or standardised score), and (iv) the study included a measure of MC. Studies were excluded if (i) they did not include primary data, (ii) the only measure of math performance was self-reported, (iii) participants were reported to have a complex neurodevelopmental disorder such as autism spectrum condition (ASC), or (iv) the only measure of MC was a broad measure of selfregulation as defined by Zimmerman (1989; i.e. it included other variables such as motivation and effort).

\section{Study Selection}

Searches yielded 2509 records. These were exported into EndNote Desktop, and 524 duplicates were removed. Two researchers independently screened the titles, abstracts, and

Table 1 The Search Terms Inputted into Databases to Identify Relevant Studies

\begin{tabular}{lll}
\hline Metacognition & Math & Performance \\
\hline Metacogniti* & Math* & Performance \\
"Meta-cogniti*" & Arithmetic & Achievement \\
"Judgment* learn*" & Numeracy & Grade \\
Metamemor* & Statistics & Score \\
"Meta-memor*" & & Mark \\
Metacomprehen* & & \\
"Meta-comprehen*" & & \\
Metaknowledge & & \\
"Meta-knowledge" & & \\
"Metacognitive monitoring" & & \\
"Meta-cognitive monitoring" & & \\
Overconfiden* & & \\
"Over-confiden*" & & \\
"Snder-confiden*" & & \\
\hline
\end{tabular}

Note. The Boolean operator "OR" was applied to the words within each column and the operator "AND" was applied to combine the three columns of words. 
keywords of the remaining 1985 records for relevance by applying the inclusion criteria stated above. This process was carried out using the web application, Rayyan (Ouzzani et al. 2016). Cohen's Kappa indicated substantial agreement between the two researchers regarding the inclusion or exclusion of records $(\kappa=.77)$. Conflicts were resolved using the consensus model with reference to the inclusion criteria. Following this process, the full texts of 115 papers were retained for secondary screening.

Where the full text of a study was unavailable $(n=16)$, we contacted the corresponding author to request the paper. The authors of four studies were contacted, and two replied by sending the relevant paper. Where a contact address was not available, or the author did not reply, the paper was requested via the University of Southampton inter-library loan service ( $n$ $=14$ requested, $n=10$ received). Six of the retrieved papers were not in English. Two of these papers were translated for screening using the online translation programme, Google Translate, and four papers were read and screened by native speakers.

Two researchers, who were blind to the decision of the other, read the full texts of the 115 records to further consider eligibility to the current review. Cohen's Kappa indicated substantial agreement between the two researchers regarding the inclusion or exclusion of studies at this stage $(\kappa=.61)$. Disagreements were resolved using the consensus model, and on two occasions, discussions took place with a third researcher to further consider inclusion. To avoid duplication of samples, where data was reported from the same participants in more than one study, the paper that reported the largest number of participants was included. If the number of participants was equal, the earliest study was included. Where the author(s) had measured MC and math performance but had not reported the association between the two $(n=6)$, we contacted the author(s) to request this information. Two authors responded, one author provided the required data, and one reported that this information was not available. In total, 84 papers were excluded during secondary screening. Supplementary Materials: Table B shows the reason for exclusion for papers. The procedure of how the final sample of studies was reached in the qualitative synthesis $(n=31)$ and quantitative synthesis $(n=29)$ is shown in Fig. 1.

\section{Data Extraction}

We extracted key data for the quality assessment of each paper and for the meta-analysis (see Table 2). The data of included papers were extracted by the first researcher. A second researcher checked the extracted data from $35 \%$ of studies (11 of 31) and agreed that this was accurate. Where only some participants within a paper fitted the inclusion criteria (e.g. a typically developing control group in a study primarily focused on individuals with ASC), data were extracted for typically developing participants only. For longitudinal studies $(n=3)$, time 1 data was extracted.

\section{Quality Assessment}

Two researchers independently assessed the quality of each study using the Critical Appraisal Skills Programme (2018). The checklist includes 12 questions and two sub-questions (14 items in total). Two questions are open-ended. Question $6(\mathrm{a}, \mathrm{b})$ was removed because it relates to longitudinal data and was not relevant to the current review. One item asked how precise the results were. We used the remaining nine items to generate a scoring system whereby a yes response scored 1 and can't tell or no both scored 0 . Higher scores therefore reflected greater 


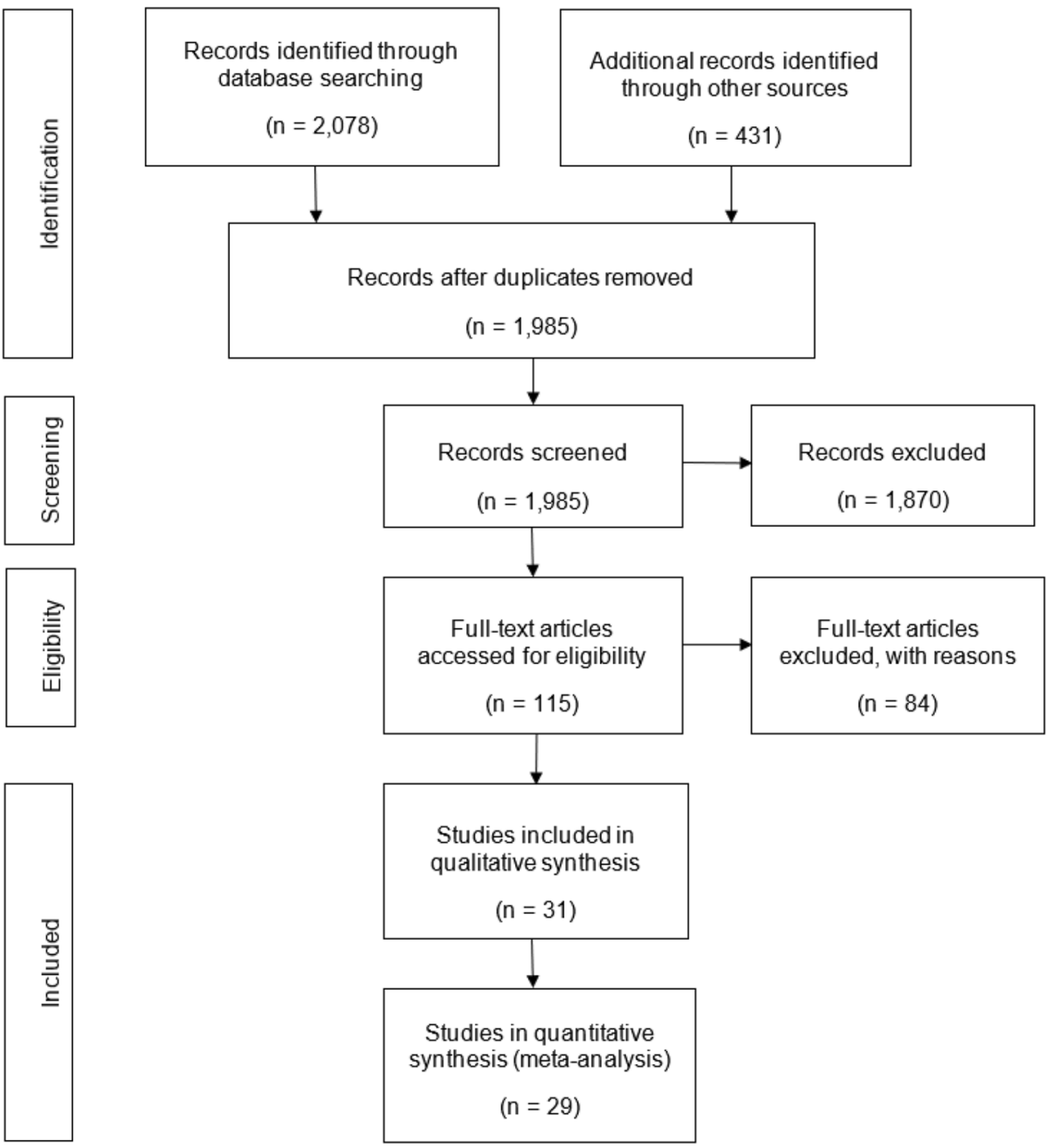

Fig. 1 The process by which the final sample of studies was reached in the current systematic review and metaanalysis

methodological quality. A table of the adapted checklist items is included in Supplementary Materials Table C.

\section{Analytic Strategy}

All analyses were conducted in R environment.

\section{Main analysis}

Pearson's $r$ coefficients reported by primary studies were converted into Fisher's Z (Borenstein et al. 2009). These effect sizes were then categorised according to the math measure (simple vs. complex vs. unclear) and to reflect the MC measure (online vs. offline) based on the distinction proposed by Veenman and van Cleef (2019) (Fig. 2). Several studies reported more 

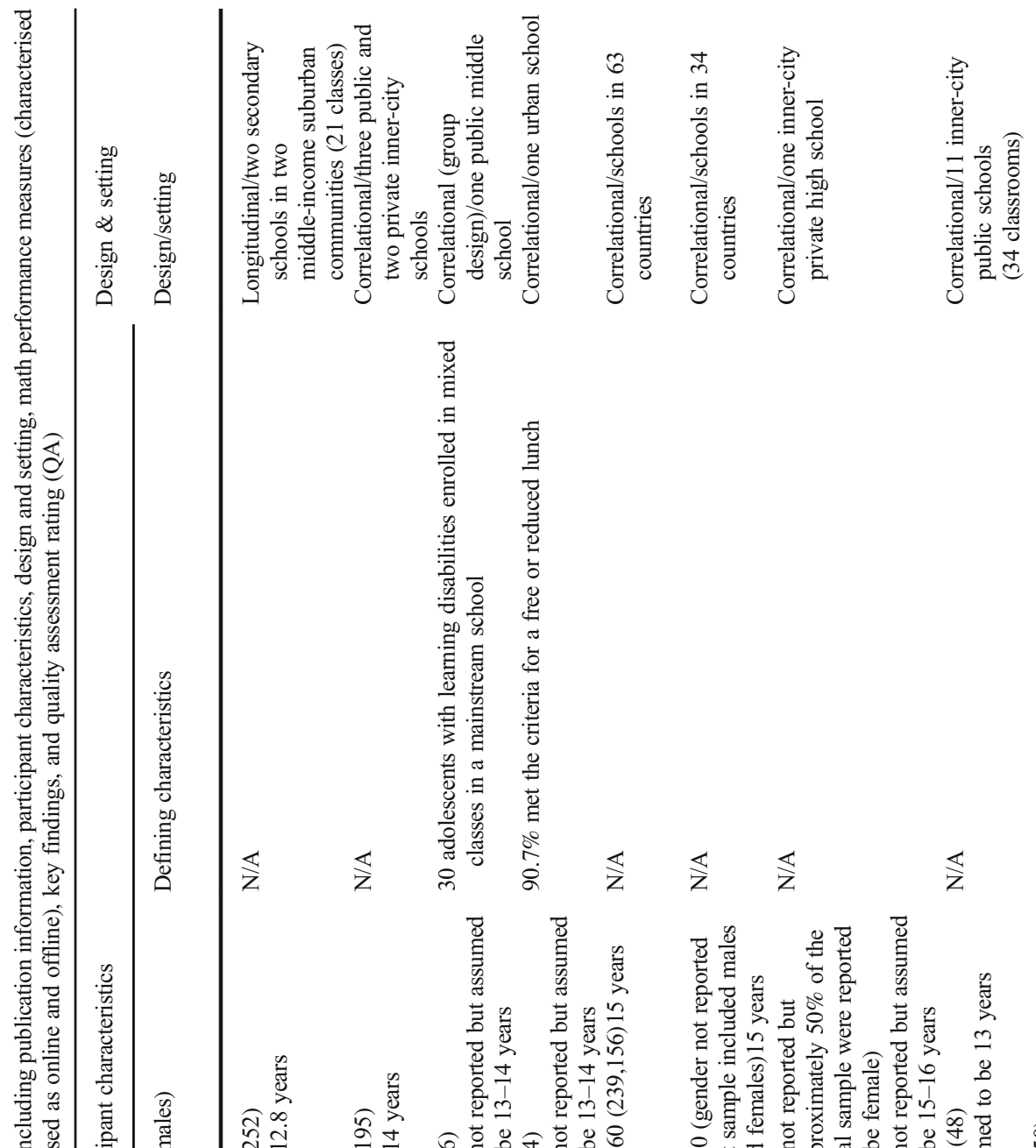

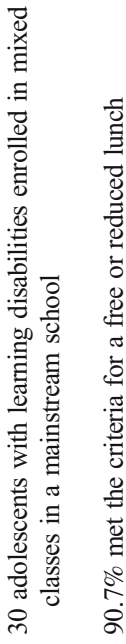

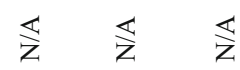

$\overleftrightarrow{\mathrm{Z}}$

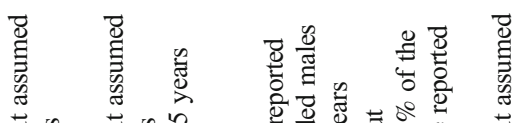

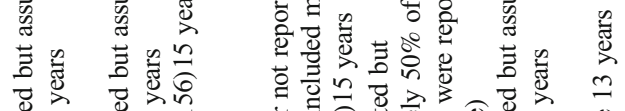

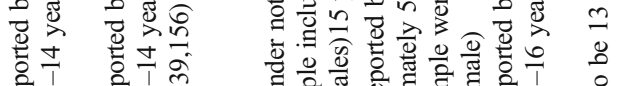

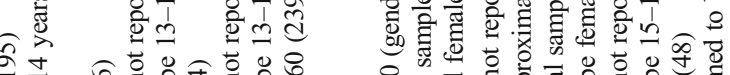

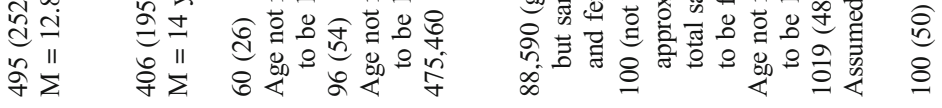

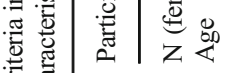

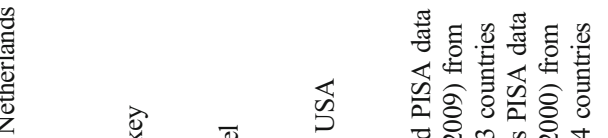

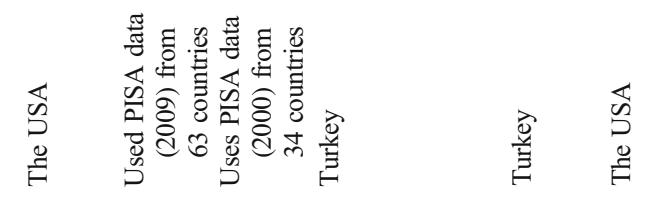

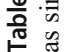

音或

递

莺

苟

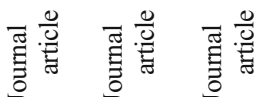

롤

产

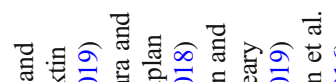

6

范令

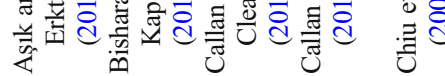

总总

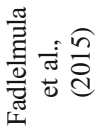




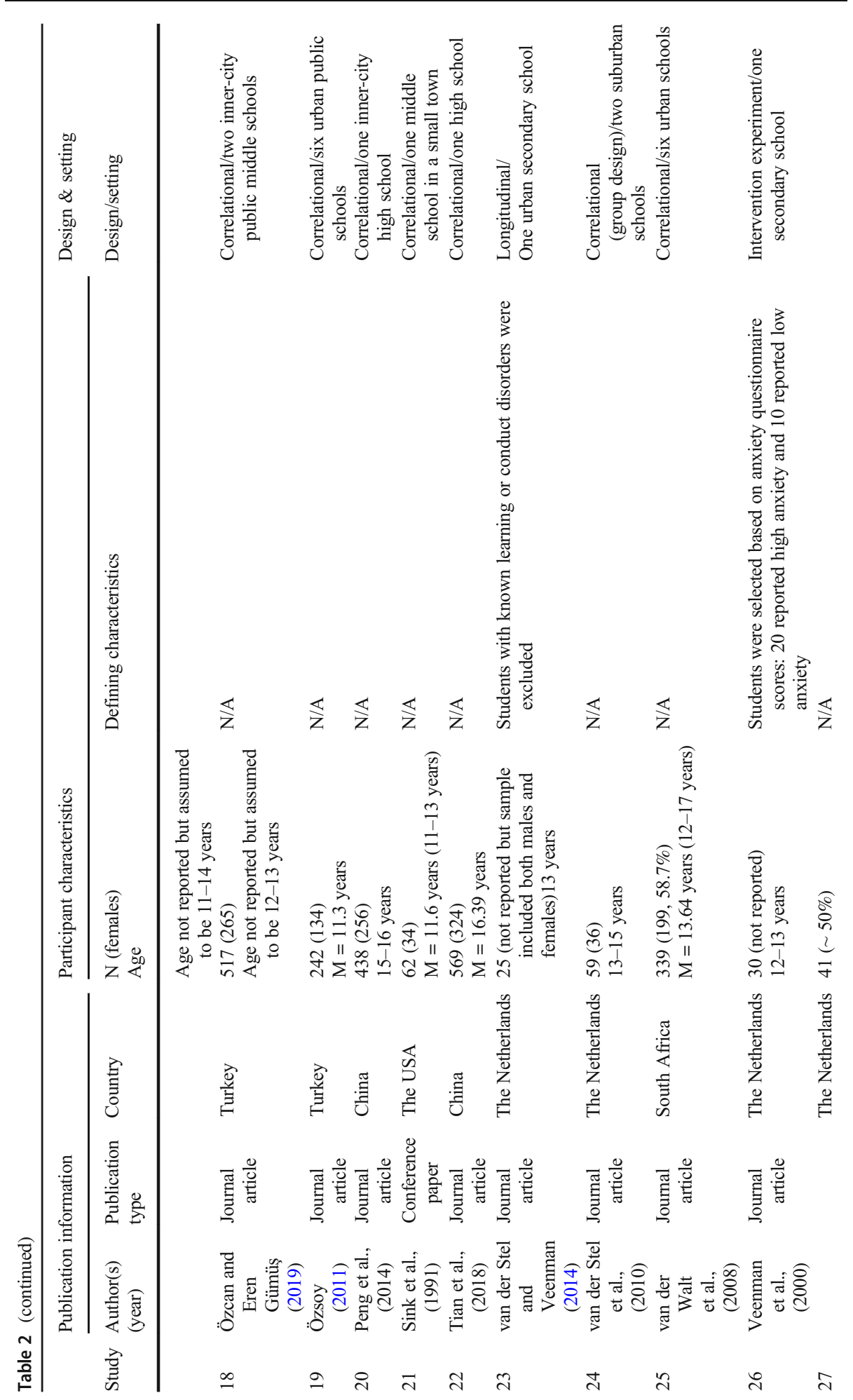




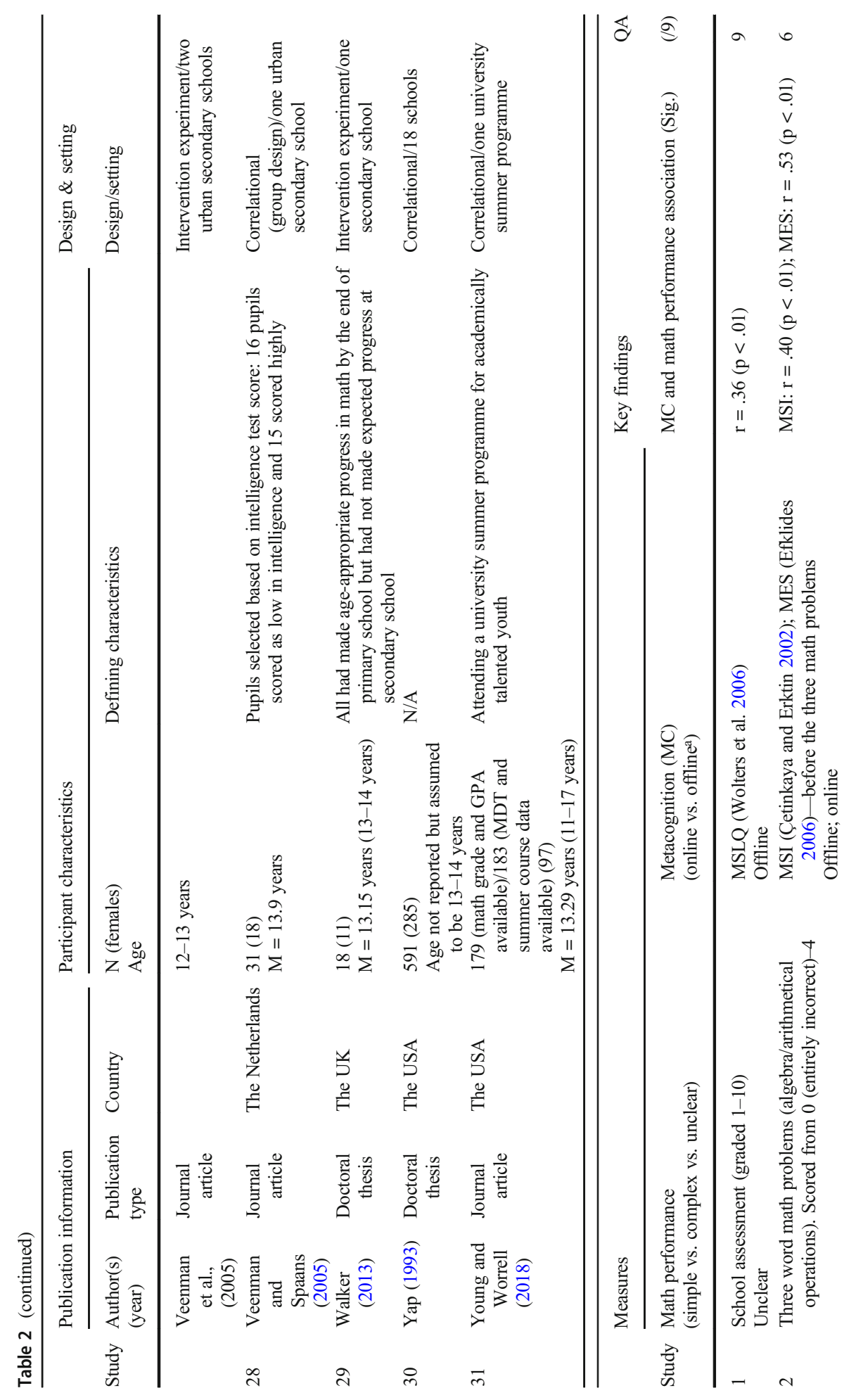




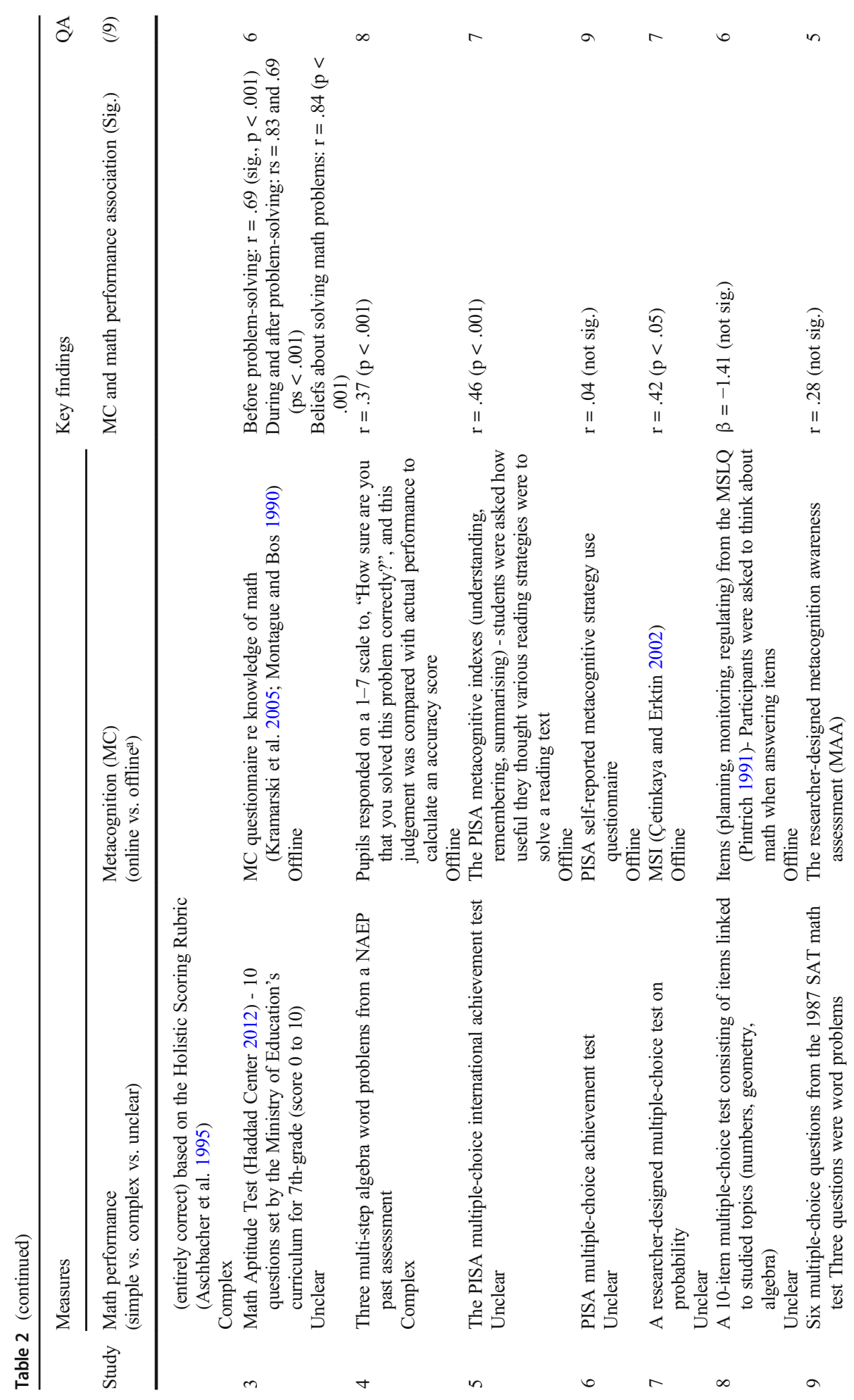




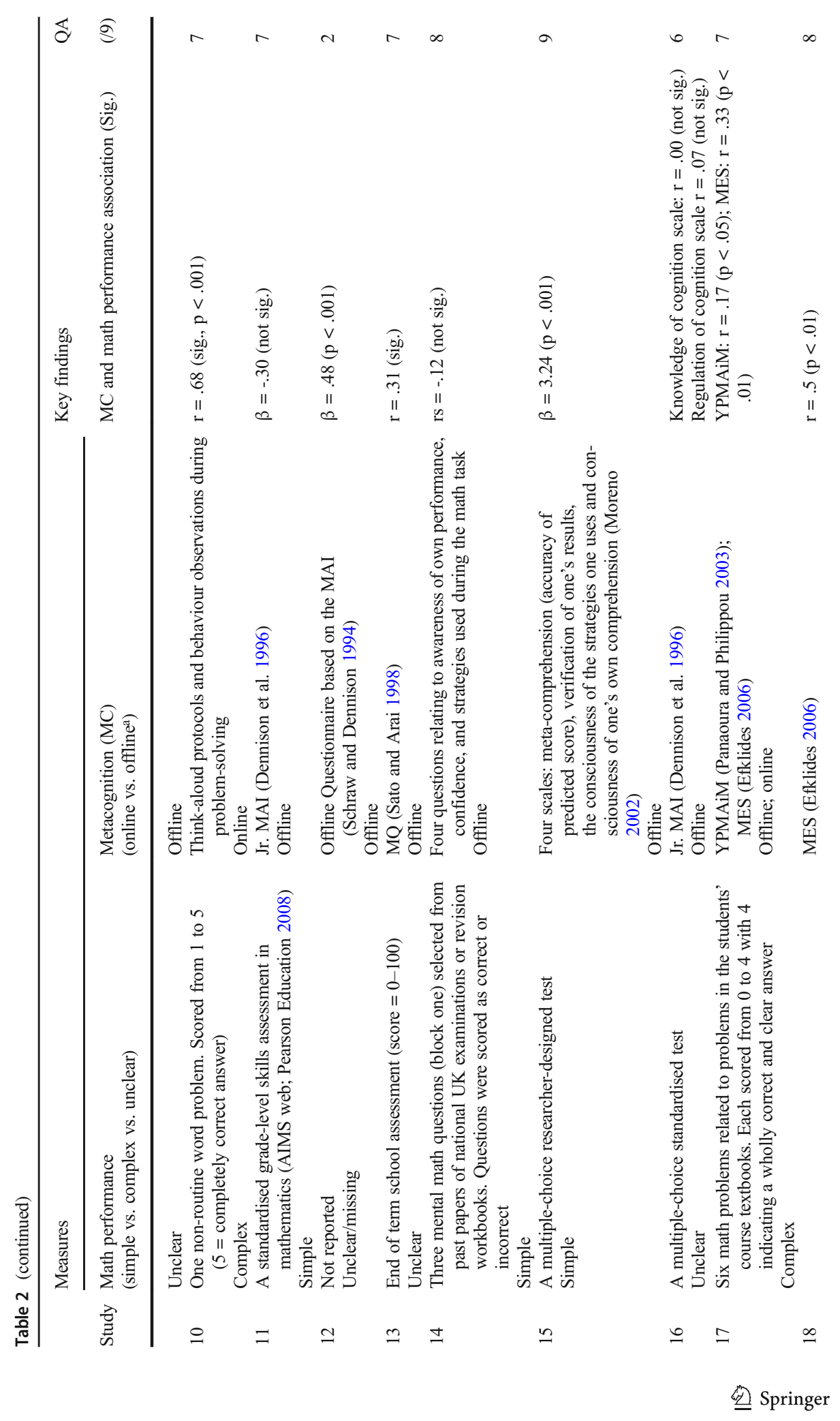




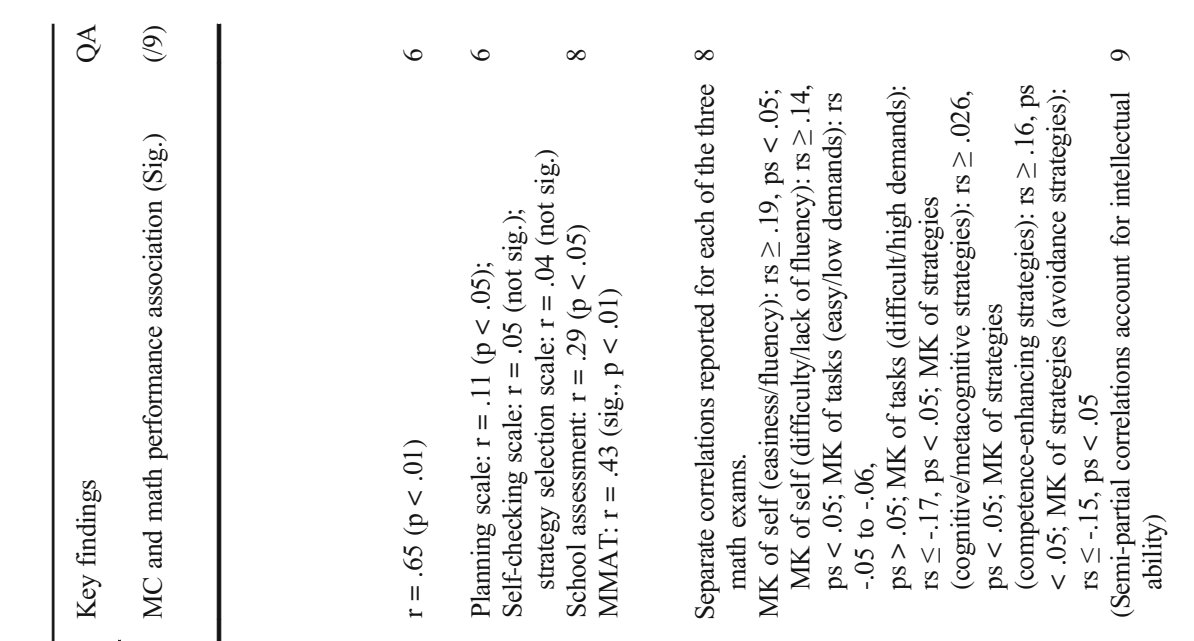

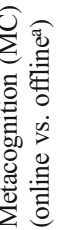

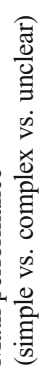

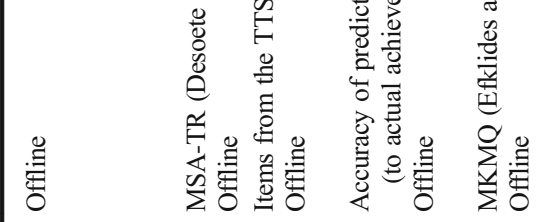

ஓ

ஓे

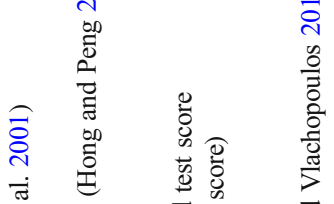

స 0 क

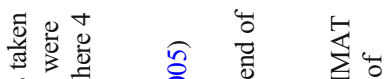

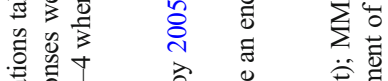

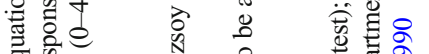

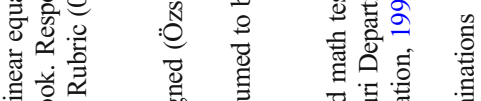

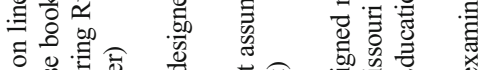

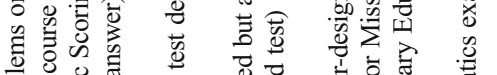

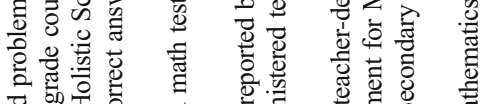

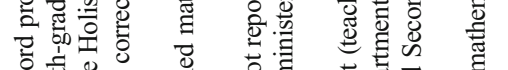

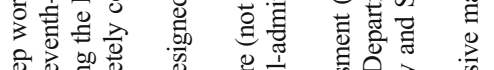

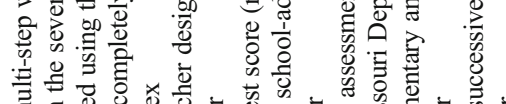

.

떵 를

冚

t)

马

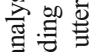

ब

远

응 है

뭉 च

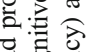

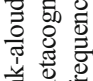

音迅

造

ذั

ฐ

छ

링

番宫

范

응 흥

뭉 믈

焉

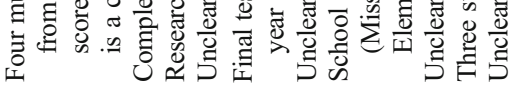

$\stackrel{\text { ก }}{2}$ ส

$\ddot{2}$ 


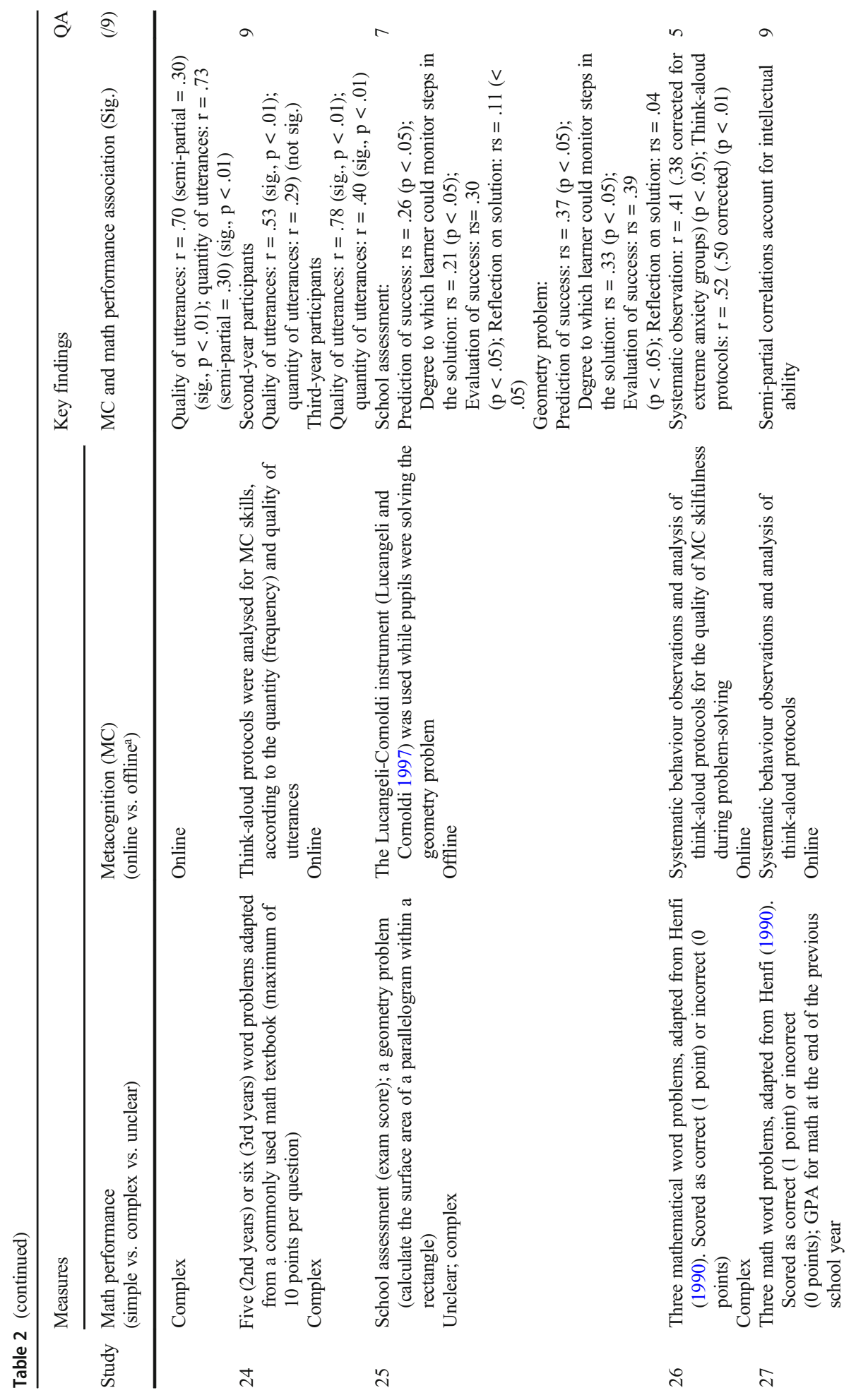




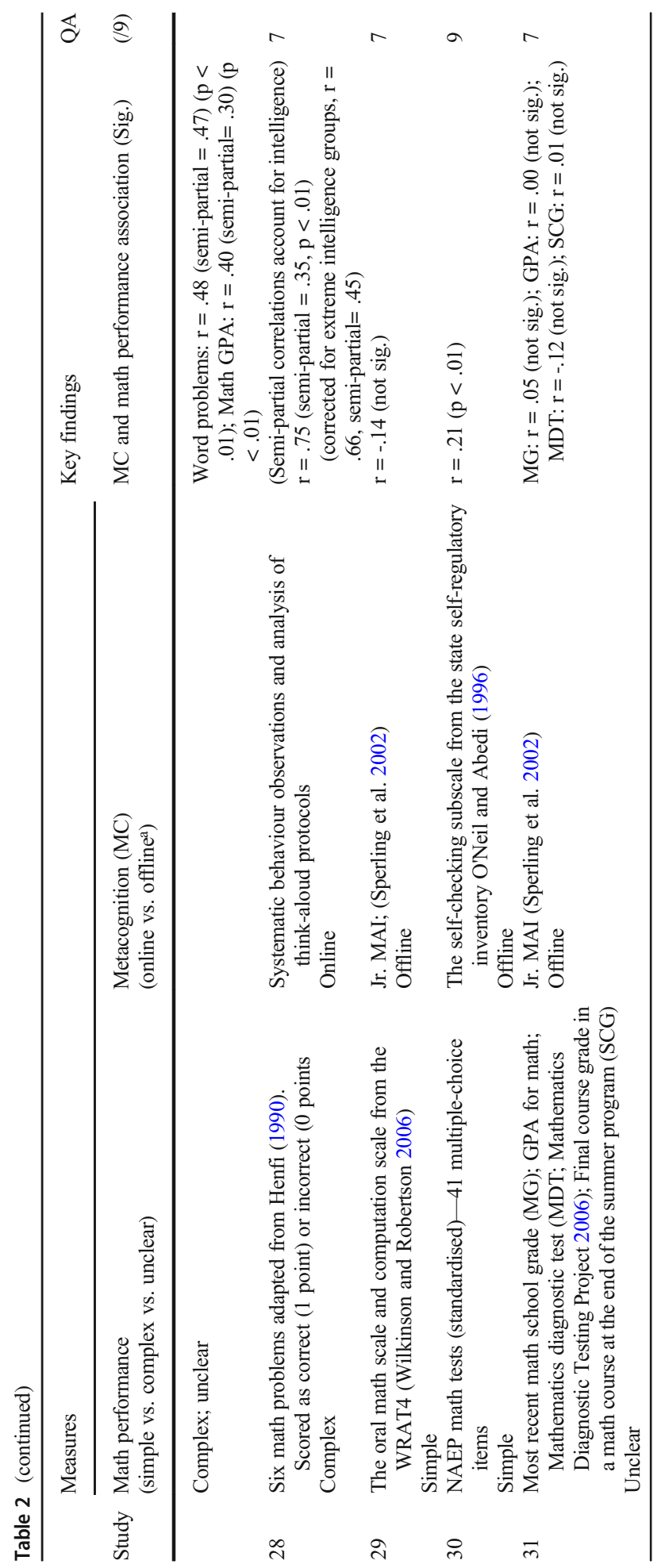

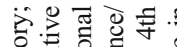

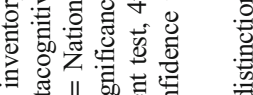

$\sum^{2} \frac{\pi}{2}$

竞

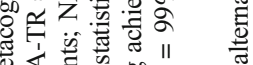

$\sum \int_{n=0}$.

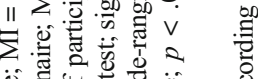

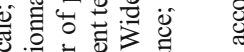

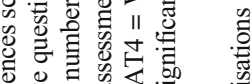

ब.

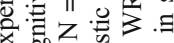

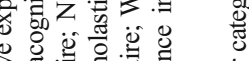

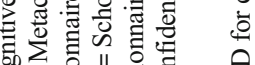

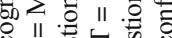

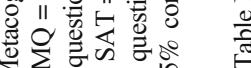

$\sum_{i=1}$ on

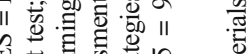

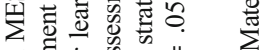

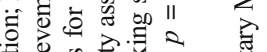

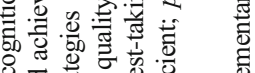

च

है कौ

II

$\sum$ 혀용

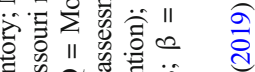

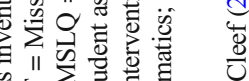

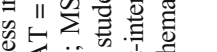

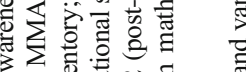

3

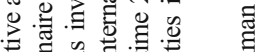

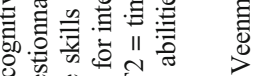

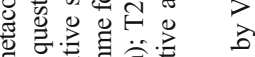

घ

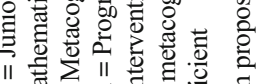

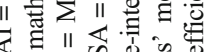

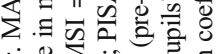

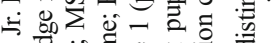

هั

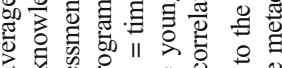

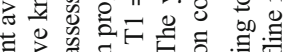

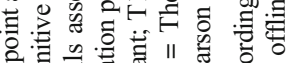

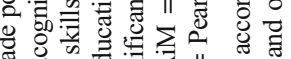

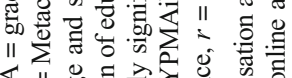

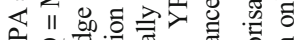

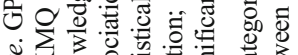

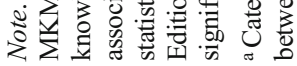


than one effect size as a result of multiple MC or math measures being used to quantify this association. Moreover, several research groups have conducted multiple studies across different publications. To account for non-independence, a two-stage random effects multivariate meta-analysis was performed (using the "metafor" and "clubSandwich" packages in R; Pustejovsky and Tipton 2021; Viechtbauer 2010). In addition to the multivariate structure, the data had some forms of hierarchical structure (i.e. one study included two independent groups, both having completed two outcomes). For this study, we assumed that the groups were entirely independent so that the number of independent studies in the model was 30 .

Following the approach recommended by Pustejovsky and Tipton (2021), we started analysing data by conducting a random effects multivariate meta-analysis known as subgroup correlated effects. In this model, we included random effects for each outcome within each study and each research group. We used a diagonal variance structure and a restricted maximum likelihood estimation. To implement this model, we had to impute the covariance matrix for all primary studies. This was performed using the "clubSandwich" package. We used the subgroup option proposed by this package to consider the categorisation of the effect sizes according to the math and MC measures. This analysis assumes a mean correlation of $r=$ 0.8 between effect sizes coming from the same study and category. We computed clusterrobust standard errors. We clustered the standard errors by research group to account for the possibility of dependence across studies conducted by the same group. Even when this model converged, the inspection of the profile likelihood plot suggested some overparameterisation. Therefore, we simplified the model by deleting the random effects for the research group. Even if research group was no longer included in our working model, we still maintained the clustering of standard errors by this factor to address the potential dependency. Throughout the manuscript, the model described here is referred to as the "primary model".

We then reassessed the pooled effect size of the association between MC and math performance using different statistical approaches. Here, the overall association of math with $\mathrm{MC}$ was reassessed by (i) refitting the primary model, but assuming different correlations between effect sizes of a same study and category (four other values were assessed: 0.05, 0.2, 0.5 and 0.95 ); (ii) refitting the primary model, but without classifying effect sizes according to math performance and $\mathrm{MC}$ measure when imputing the covariance matrix, and without including the factor in the random effects; (iii) using a classic robust variance estimation approach to handle the dependence of effect sizes within studies (Tipton 2015); and (iv) using the aggregation approach (see Borenstein et al. 2009) to handle the dependence of effect sizes within studies. These approaches did not affect the statistical significance of this analysis.

\section{Sensitivity Analyses}

A total of five additional analyses were conducted. First, we performed a leave-one-out analysis (i.e. we re-ran our primary model, but leaving out each study sequentially) to assess the impact of each study on the pooled effect size. Models converged for all exclusions except one. Second, we re-ran our primary model but excluded effect sizes with standardised residuals superior to 2 (results of this analysis are not reported because no effect size was associated with a standardised residual superior to 2), with hat values superior to twice the mean of hat values (five effect sizes were excluded), or with Cook's distance superior to twice the mean of Cook's distance (six effect sizes were excluded). Third, we re-ran our primary model, but excluding studies with less than $80 \%$ power to detect the effect size of the study with the lowest variance (eight studies and 12 effect sizes were excluded). Fourth, using the results of our quality 


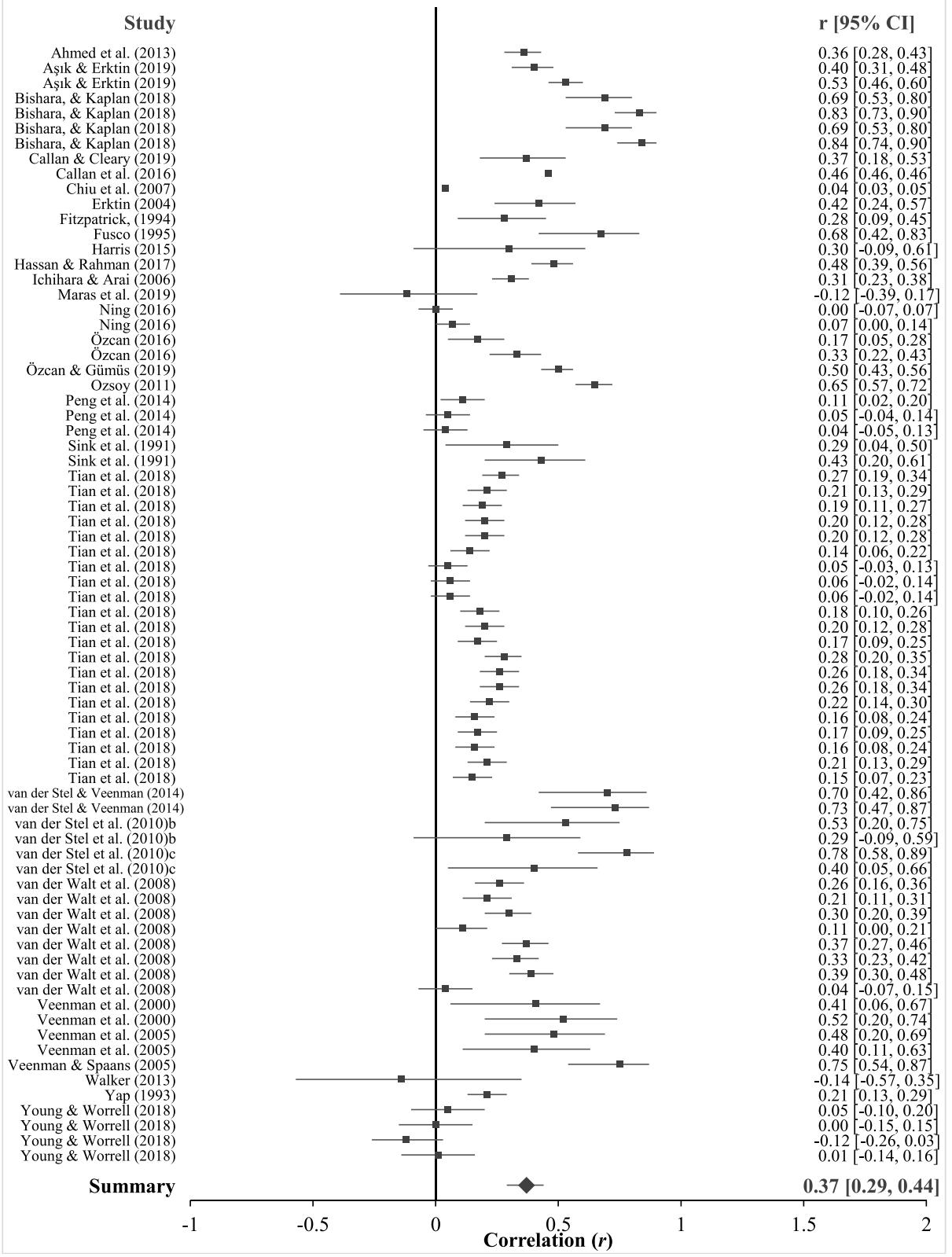

Fig. 2 A forest plot of the effect sizes for each study and the overall effect size. The boxes represent the effect size (r) for each study, the lines represent $95 \%$ confidence intervals, and the diamond represents the synthesised effect size. b Second-year students. c Third-year students 
assessment, we identified three questions in the Critical Appraisal Skills Programme (2018) relating to critical biases (see Supplementary Material C). Six studies (28 effect sizes) had at least one unclear/high risk of bias score (indicating by an unclear or no response to the item), and we re-ran our primary excluding studies these studies. Finally, we re-ran our primary model but excluding the two very large PISA studies $(n=2)$.

\section{Moderation Analysis}

Because we anticipated that effect sizes would differ depending on the MC measure and assessment of math performance, we ran a moderation analysis assessing the influence of these factors. This analysis investigated whether there were significant differences in the pooled effect sizes of studies that used online versus offline measures of MC and studies that used simple versus complex math assessments. To consider the different distinctions in the literature between online and offline measures of $\mathrm{MC}$, this subgroup analysis was carried out four times. In all four analyses, self-reported questionnaires were classed as offline, and think-aloud protocols and behaviour observations were classed as online. However JOLs, confidence judgements, and calibration scores were classed differently between analyses. The four analyses carried out were (i) online defined as not self-reported (JOLs, confidence judgements, and calibration scores classed as offline in line with the definition proposed by Veenman and van Cleef 2019), (ii) online defined as pertaining to a specific task at hand (i.e. JOLs, confidence judgements, and calibration scores classed as online, in line with the definition proposed by Saraç and Karakelle 2012), (iii) online defined as taking place during a task (JOLs, confidence judgements, and calibration scores classed as online where they were carried out during a task, with those carried out before/ after a task classed as offline, as in Craig et al. 2020), and (iv) JOLs, confidence judgements, and calibration scores (i.e. student-reported MC score relevant to a specific task at hand) categorised separately from other online and offline measures.

Last, we considered the combination of MC measures and math assessment. We combined the math performance (according to its complexity: simple vs. complex vs. unclear) and the MC measure (according to Veenman \& van Cleef's categorisation) into a single measure. This combination yielded a moderator with six potential modalities (e.g. complex math task conducted online; simple math task conducted offline). We found that five combinations were explored in primary studies and that only four were represented by at least two studies/research groups. We conducted a meta-regression with this factor as the moderator and without including a model intercept. This analysis generated a pooled effect size for each of the four combinations of math performance and MC measure assessed by at least two studies/research groups. Raw and adjusted (with a Bonferroni correction) $p$ values are also reported.

\section{Results}

Of 1985 papers (115 full texts) screened for eligibility, 31 studies met the inclusion criteria. Details of the included studies, including quality assessment ratings, are displayed in Table 2. Studies included in this review are peer-reviewed journal articles $(n=25)$, unpublished doctoral theses $(n=4)$, and conference research papers $(n=2)$. Included studies were published/made available between 1991 and 2019. One study included data 
from students in 34 countries using the PISA 2000 database and another used data from students in 63 countries using the PISA 2009 database. Other studies were conducted in 11 countries including the Netherlands $(n=6)$, Turkey $(n=6)$, Israel $(n=1)$, the USA $(n=7)$, Malaysia $(n=1)$, the UK $(n=2)$, Japan $(n=1)$, Spain $(n=1)$, Singapore $(n=1)$, China $(n$ $=2$ ), and South Africa $(n=1)$. Collectively, the 31 papers included 572,559 participants. Apart from the two studies which used PISA data and involved high numbers of participants $(88,590$ and 475,460), the number of participants ranged from 18 to 1019. All participants were aged 11-17 years. There was inconsistent reporting of age; some studies reported mean age and/or age range, and some studies did not report age $(n=9)$. In these instances, age was derived from the reported stage of schooling (see Table 2). The lowest reported mean age was 11.3 years, and the highest was 16.39 years. Twenty-six (/31) studies reported the sex/gender split of participants; from these studies, the total participant sample was 483,145 , and of these, 243,061 (50.3\%) were female.

\section{Qualitative Results}

Nineteen of the 31 papers reported a statistically significant positive association(s) between $\mathrm{MC}$ and math performance $(p \mathrm{~s}<.05)$. Eight studies reported positive association(s) that were not statistically significant. Four studies reported mixed findings (i.e. more than one correlation was reported due to measuring $\mathrm{MC}$ and/or math performance using more than one measure/ scale, and at least one correlation was significant, and one correlation was not significant).

\section{Quality Assessment}

We utilised the scoring system whereby increased yes responses in the adapted CASP questionnaire (2018) are indicative of higher quality research. In seven studies, we rated all nine items as yes, six studies were given eight yes responses, ten were given seven yes responses, five were given six, two were given five, and one study was awarded two yes responses (see Supplementary Materials E for responses for each item).

All studies addressed a focused issue that was evidenced by clear research aims, and all were considered to be sufficiently precise. Correlations/associations were reported with at least $95 \%$ confidence $(p<.05)$ and, in most cases, with greater confidence (e.g. 99\%, $p<$ $.01)$. Generally, participants were recruited in a way that meant they were likely to be representative of their cohort. However, $n=7$ studies did not report how participants were recruited.

Most studies $(n=18)$ used pre-published and validated questionnaires. One study used a measure designed by the researcher. In this case, the measure had high inter-rater reliability, but there was no reference to validity testing. Most studies $(n=25)$ used acceptable measures of math performance. In two studies, the measure of math performance was unclear. One study did not report how math performance was measured, and the second provided unclear information. Additionally, one study reported coefficient alphas that fell within a questionable range $(\alpha \mathrm{s}<.70)$, one study used a measure on a single topic within mathematics that was reported to be particularly difficult for teachers to teach, and in one study, the selection of question items was made on the basis that males had previously out-performed females on chosen questions.

The impact of confounding factors on the relationship between $\mathrm{MC}$ and math performance was not consistently considered. Three studies reported semi-partial correlations between MC 
and math performance to control for the contribution of general intelligence. Most studies included participants who were relevant to the population of interest in the current review. It was unclear whether some studies that selected participants based on specific characteristics (e.g. learning disability, having made below-expected progress in math, having below or above average anxiety, or being academically talented) were representative of 11-16-year-olds. Furthermore, one study included only female participants.

\section{Meta-Analysis Results}

Correlations between MC and math performance were available for 29 (/31) studies, and these were included in the meta-analysis (participant $N=570,575, n=30$ independent populations, $k$ $=74)$.

\section{Small Study Effects}

We assessed small study effects using a modified version of the Egger's test (Egger et al. 1997). More precisely, we re-ran our primary model including the inverse of the sample size (or its square root) as the moderator. These analyses showed some evidence of small study effects $(p=.052)$. A very similar result was obtained when using the standard error as moderator $(p=0.045)$. However, when adjusting our primary model by the standard error, the inverse of the sample size, or its square root, the pooled effect size remained systematically statistically significant (all $p$ values $<.01$ ).

\section{Primary Analysis}

The primary analysis revealed a positive and significant association between $\mathrm{MC}$ and math performance $(r=.37,95 \% \mathrm{CI}=[.29, .44], p<.001)$.

\section{Heterogeneity}

Heterogeneity was significant and high in the primary analysis $(Q(73)=16646.6539, p<$ .001 ), indicating substantial variation in effect sizes across included studies (Higgins et al. 2003). To quantify inconsistency, we refitted our primary model without including random effects and we computed an overall $I^{2}$ statistic across all outcomes (see Jackson et al. 2012). The results of this analysis revealed an $R^{2}$ statistic superior to $99 \%$, meaning that almost all the variability in effect estimates can be attributed to heterogeneity rather than sampling error. Several sensitivity analyses were then conducted to investigate the source of this heterogeneity and assess the robustness of our primary result (see Table 3). In all of these analyses, the heterogeneity and the pooled effect size of the association of math with MC remained statistically significant. While these analyses suggest that the association between math and $\mathrm{MC}$ is robust, they failed to identify the source of heterogeneity. Several moderation analyses were then conducted for this purpose.

\section{Moderator Analysis}

Subgroup analysis explored whether measure of MC (online vs. offline) moderated the relationship between $\mathrm{MC}$ and math performance. To consider the different distinctions in the 
Table 3 Results from sensitivity analyses

\begin{tabular}{lllll}
\hline Sensitivity analysis & $\begin{array}{l}\text { Pooled effect size } \\
(r[95 \% \mathrm{CI}])\end{array}$ & $\begin{array}{l}\text { Significance of pooled } \\
\text { effect size }(p)\end{array}$ & $\begin{array}{l}\text { Heterogeneity } \\
(Q)\end{array}$ & $\begin{array}{l}\text { Significance of } \\
\text { heterogeneity } \\
(p \text { value of } Q)\end{array}$ \\
\hline $\begin{array}{l}\text { Leave-one-out } \\
\begin{array}{l}\text { Excluding large hat values } \\
\text { Excluding large Cook's }\end{array}\end{array}$ & $\begin{array}{l}0.32[0.23,0.40] \\
\text { values }\end{array}$ & $\begin{array}{c}\text { All }<.001 \\
.003\end{array}$ & All $\geq 1206$ & All $<.001$ \\
$\begin{array}{l}\text { Excluding studies with low } \\
\text { statistical power }\end{array}$ & $0.36[0.28,0.43]$ & $<.001$ & 16621.59 & $<.001$ \\
$\begin{array}{l}\text { Excluding studies at "high } \\
\text { risk of bias" }\end{array}$ & $0.39[0.31,0.47]$ & $<.001$ & 998.49 & $<.001$ \\
$\begin{array}{l}\text { Excluding the two PISA } \\
\quad \text { studies }\end{array}$ & $0.37[0.26,0.48]$ & $<.001$ & 16587.09 & $<.001$ \\
\hline
\end{tabular}

literature between online and offline measures, this analysis was carried out four times. First, we considered JOLs, confidence judgements, and calibration scores classed as offline so that we compared think-aloud protocols and behaviour observations versus self-report questionnaires, JOLs, confidence judgements, and calibration scores. In the subsequent reporting of results, $n$ indicates the number of independent samples and $k$ indicates the number of effect sizes. In this analysis, the pooled effect size was significantly larger when online MC measures were employed $\left(n=9, k=14, r=.54, I^{2}=79 \%\right)$ than when offline measures were employed ( $n$ $\left.=23, k=60, r=.30, \mathrm{I}^{2}>99 \% ; p=.034\right)$. Second, when JOLs, confidence judgements, and calibration scores were classed as online so that we compared JOLs, confidence judgements, calibration scores, think-aloud protocols, and observations versus offline questionnaires, the pooled effect size was significantly higher for online studies $\left(n=16, k=29, r=.46, I^{2}=90 \%\right)$ than for offline studies $\left(n=16, k=45, r=.28, I^{2}>99 \% ; p=.034\right)$. Third, when JOLs, confidence judgements, and calibration scores that were completed before or after each individual item during a math task were classed as online (alongside think-aloud protocols and behaviour observations) and those that were completed before or after an entire math task were classed as offline (alongside self-report questionnaires), the pooled effect size was significantly higher for studies that measured MC during a math task $(n=14, k=26, r=$ $\left..48, I^{2}=91 \%\right)$ than not during a math task $\left(n=18, k=48, r=.28, I^{2}>99 \% ; p=.027\right)$. Finally, when JOLs, confidence judgements, and calibration scores were coded separately to other online and offline measures, an omnibus test showed that the effect estimates for the three categories (online, offline, JOL/accuracy) were not equivalent $(p=.008)$. The pooled effect sizes and $I^{2}$ statistics for online $(n=7, k=12)$, offline $(n=16, k=45)$, and JOL/accuracy scores $(n=9, k=17)$ were $r=.59, I^{2}=30 \% ; r=.28, I^{2}>99 \%$; and $r=.38, I^{2}=92 \%$, respectively. Collectively, the results of this analysis suggest that consideration of offline versus online measures was not sufficiently precise to achieve homogeneity.

Similar difficulties to obtain homogeneous categories were observed when performing a moderation analysis considering math measure as the moderator (comparing effect sizes for studies that used simplex and complex math measurement and those where measurement was unclear). This analysis showed a significant omnibus test $(p<.05)$, indicating differences in the pooled effect sizes between effect estimates produced by complex math measurement $(n=$ $\left.12, k=21, r=0.48, I^{2}=87 \%\right)$, simple math measurement $\left(n=4, k=4, r=0.10, I^{2}=87 \%\right)$, and unclear measurement $\left(n=16, k=49, r=0.33, I^{2}>99 \%\right)$. However, the number of studies using simple math tasks was small and inconsistency remained high in each category. 
The observed heterogeneity motivated a more precise exploratory moderation analysis combining both math and MC measures. An omnibus test revealed that the effect estimates marginally differed between the categories $(p=0.057)$. More precisely, a very large effect size was observed when an online measure of MC and a complex math task were employed $(n=9$ $\left.k=13, r=0.54, I^{2}=79 \%\right)$. Moderate effect sizes were observed when an offline measure of MC and complex $\left(n=5, k=8, r=0.35, p=.001, I^{2}=86 \%\right)$ or unclear math tasks $(n=15, k=$ $48, r=0.32, I^{2}>99 \%$ ) were employed. A small effect size was observed when an offline measure of $\mathrm{MC}$ and a simple math task were employed $\left(n=4, k=4, r=0.10, I^{2}=87 \%\right)$.

\section{Discussion}

The current paper investigated the association between $\mathrm{MC}$ and math performance in adolescents aged 11-16 years via a systematic review and quality assessment of existing research. In addition, it included a meta-analysis to investigate the strength of the association between MC and math performance in adolescents across studies. The meta-analysis also considered whether measurements of MC (online vs. offline) and math performance (simple vs. complex) and their combination were important in understanding links between $\mathrm{MC}$ and performance in math tests. The systematic search yielded 31 studies. The synthesis of 74 effect sizes from 29 of these studies ( $\mathrm{N}=570,575,30$ independent populations) indicated a significantly positive, medium-sized correlation between MC and achievement in math $(r=.37, \mathrm{CI}=[.29, .44], p<$ $.001)$. This relationship indicates that in a key stage of education where students are working towards exams critical for progression in further education or career pathways, individuals who showed or reported increased MC skill also performed better in math tasks. While the calculation of a pooled effect size generates an important understanding of the data, the association between $\mathrm{MC}$ and math performance indicated significant heterogeneity between studies. Moreover, efforts to reduce heterogeneity (via e.g. a sequential leave-one-out analysis, the removal of outliers, the exclusion of studies with low statistical power or possible risk of bias, exclusion of the two very large PISA studies) were unsuccessful in identifying its source.

Subgroup analyses explored moderators that may be potentially important in understanding whether theoretical and empirical differences between studies underpinned heterogeneity across studies. The current paper replicated the findings from previous reviews which have found that online (vs. offline) MC measures were most associated with performance in math assessments (Dent and Koenka 2016; Ohtani and Hisasaka 2018). We extended these analyses to more closely utilise researcher definitions of online versus offline MC across four separate analyses (see Saraç and Karakelle 2012; Veenman and van Cleef 2019). These considered whether MC processes were used by adolescents as they completed the math problem (e.g. using think-aloud methods), or occurred immediately before or after its completion (e.g. using JOL or calibration scores), or were measured outside of the math task (i.e. using questionnaires). The results showed that the use of online measures were consistently associated with the largest effect size across analyses. Moreover, while heterogeneity remained high in most analyses, we found that when effect sizes were separated by MC measure (online vs. offline vs. $\mathrm{JOL} /$ calibration score), the 12 effect size estimates for the online measure were relatively consistent $\left(I^{2}=30 \%\right)$ and strong ( 11 out of 12 effect size estimates were stronger than $r=.40$ ). This finding supports the proposition that the active use of $\mathrm{MC}$ during math problems is associated with increased performance. Because only two research groups produced these 12 
effect sizes, future studies conducted by different research groups will be important to assess the robustness of this finding.

Building on previous research (e.g. Mokos and Kafoussi 2013; Verschaffel et al. 2010; review by Jordano and Touron 2018), we further investigated in a subset of studies $(n=16)$ whether increased complexity of the math task was most linked with the use of MC processes and could potentially explain heterogeneity across studies. In support of the hypothesis, the results showed that the effect size was largest when MC measures were linked to more complex math tasks; however, heterogeneity for all analyses remained high and the number of papers that included simple math tasks was small. Further exploratory moderation analyses showed that when combining our two moderators, the combination of an online MC measure and a complex math task produced the largest effect size $(r=.54)$. Conversely, the combination of an MC offline measure and simple math task was associated with the smallest effect size $(r=.10)$. Though heterogeneity in these analyses also remained high, the findings provide indicative evidence that the association between $\mathrm{MC}$ and performance may be stronger when adolescents are completing tasks that demand some awareness of strategic knowledge and ability to monitor performance and control cognitive processing as they move through the math problem (see e.g. Credé and Phillips 2011; Nelson and Narens 1990).

Our moderation analyses demonstrated that the heterogeneity in the overall association between MC and performance in math tasks could not be only attributed to the MC or math measures used in primary studies. Previous meta-analyses using similar moderation approaches to explain heterogeneity between studies considering $\mathrm{MC}$ and achievement have also reported high heterogeneity (e.g. Dent and Koenka 2016; Ohtani and Hisasaka 2018; Richardson et al. 2012). Consistent with the findings in this paper, for example, Ohtani and Hisasaka (2018) reported reductions in heterogeneity for moderation analysis including comparisons of online (versus offline) tasks, though it still remained moderately high.

Given the range of MC measures used in this evidence base (Gascoine et al. 2017), the varied contexts in which measures are taken (e.g. during learning, retrospectively during testing, or outside of the learning context altogether and via $\mathrm{MC}$ questionnaire scales), and the types of information the measures are intended to generate, variability between studies is not surprising. For example, offline measures reflect more stable trait-like characteristics indicating student awareness and potential use of MC strategies in their approach to solve math problems, while online measures capture thought processes associated with working through specific material (review by Jordano and Touron 2018). One important goal for optimising the potential for math achievement in school should focus on identifying MC strategies that will help students to identify areas of the curriculum that require additional attention or study (e.g., Son and Metcalfe 2000). Gascoine et al. (2017) reported that $60 \%$ of research exploring $\mathrm{MC}$ with children and adolescents use offline questionnaires. Questions about MC that are not specifically related to curriculum content currently being learned do not, however, help students specify which areas of, e.g., math knowledge need more attention. For example, the response to the question, "I try to use strategies that have worked in the past" (Schraw and Dennison 1994), does not inform students that while they have a good understanding of geometry, they need to work more on algebra. Conversely, the generation of online item-by-item JOLs while studying math material may facilitate greater student awareness in making this type of discrimination.

This argument suggests that the process of making MC judgements during learning is neither static nor neutral (i.e. it can modify study habits that in turn can affect learning). In other words, MC judgements made during learning reflect both reactive (to guide students to 
specific material) and reciprocal (to understand what has been learned) processes. For example, several studies that have focused on JOLs suggest that the very act of making a MC judgement alters what is remembered (e.g. Fiacconi et al. 2019; Janes et al. 2018; Myers et al. 2020; Tekin and Rodiger 2020; see Double et al. 2018 for a meta-analysis). This research suggests that students who focus on the quality of their learning by providing $\mathrm{MC}$ responses impacts what is learnt. Although JOL reactivity clearly indicates a link between MC judgements and learning outcomes, the mechanisms underpinning this relationship are unclear. Furthermore, specifying how JOL reactivity might affect the relationship between MC judgements and achievement is complicated by the fact that making (versus not making) JOLs sometimes improves learning, sometimes causes learning to deteriorate, and sometimes has no effect. Furthermore, to our knowledge, no study has investigated whether the magnitude of making a JOL (or another MC judgement) about learning produces differential reactivity. For example, if a student reports low levels of confidence that they would be able to recall learnt information in a later test (e.g. Myers et al. 2020), that judgement may lead to a selective enhancement of learning, and this behaviour may result in no (or even an inverse relationship) between MC and achievement. In contrast, if low levels of confidence do not change learning behaviour, then the correlation between the JOL and learning will be higher. The consideration of the dynamic and reciprocal interaction between MC judgements with subsequent strategies for learning and achievement is less relevant to offline measures, or online measures made at test (e.g., retrospective confidence ratings), because these judgements do not have the potential to causally affect learning in the same way.

Another factor that can affect the relationship between MC measures and achievement is student ability. Students who perform poorly on a task often show poor MC insight into their own limitations, causing them to overestimate their abilities (e.g. Kruger and Dunning 1999) or give MC ratings that are poorly related to performance (e.g. Higham and Arnold 2007). With respect to lower-performing students, this effect is sometimes referred to as the "double curse" (Kruger and Dunning 1999) or the "unskilled-andunaware" phenomenon (Hartwig and Dunlosky 2014). This phenomenon may be dependent on whether the MC measure being used is clearly integrated with the material being learned. Vuorre and Metcalfe (2021) noted that if academic tests are used that permit guessing (e.g. multiple-choice tests), for example, then "metacognitive misses" (i.e. correct guesses assigned low MC rating) can undermine the relationship between the MC measure and performance. Such misses occur more often with low-performing students, thereby lowering MC accuracy specifically for those students. In tasks that do not allow MC misses (e.g. recall of learnt material), the relationship between MC and performance may remain relatively intact. While the current paper focused on specific combinations of $\mathrm{MC}$ measures (online, offline) and math performance (simple, complex), these studies suggest that further aspects of the tasks employed to measure MC and task performance can affect the MC rating/performance link.

More generally, to understand the relationship between MC measures and academic performance, we suggest it is critical to examine the specifics of both the MC measure and the measure of performance under scrutiny. This principle is true not just of MC measures, but of other academic measures as well. For example, Murayama et al. (2013) found that student self-reported intrinsic motivation and deep learning strategies were unrelated to math achievement at 11 years of age. On the surface, this finding might seem counterintuitive; however, the authors noted that students with high intrinsic motivation might have little concern about performing well on an upcoming test. Also, deep learning strategies may be slower and more 
effortful than more superficial learning strategies, which may be costly in tests written in the short term (but more effective over the long term). Collectively, these studies indicate that associations between student self-reported approaches to learning and achievement cannot be studied in a vacuum; the particulars of the measurement instruments, both those designed to measure $\mathrm{MC}$ and those designed to measure math achievement, are as fundamental to this relationship as the overarching concepts themselves.

The results of the current review and meta-analysis have gone someway to highlight that measurements of $\mathrm{MC}$, math tasks, and their combination are important in understanding associations between these variables. The methodological quality of studies in the review was acceptable or good, though there were difficulties accessing some papers. At face value, the results indicate that the use of MC strategies in learning math are best understood when this cognitive process is situated within the learning activity (via online tasks) and utilised when students are engaged with complex (versus simple) math tasks. They further indicate that existing conceptual differences between online, offline, and JOLs, confidence judgements, and calibration scores may be too simplistic. Nevertheless, the study highlighted significant heterogeneity between studies in all analyses. The discussion has focused on the measurement and dynamic interplay between MC and math achievement to start to understand this heterogeneity. It suggests that future research should focus more closely on how students utilise MC processes to change their own learning behaviour and to understand how any adjustments are reflected in learning outcomes. In addition, further studies have highlighted other factors that could potentially moderate the association between MC and math achievement and that have not been considered in existing research, including anxiety (Moran 2016) and executive functioning (Steinmayr et al. 2010) and their interaction. Moreover, the TIMSS 2019 report (Mullis et al. 2020) highlighted a complex picture with respect to identifying factors beyond the influence of student self-reported MC on math achievement that future research could explore. This focus could include, for example, whether males and females utilise MC strategy more or less effectively, or whether access to learning resources in the home and school learning environments influences the development of $\mathrm{MC}$ and its use in the classroom.

Supplementary Information The online version contains supplementary material available at https://doi.org/ 10.1007/s10648-021-09620-x.

Funding This work formed part of a doctoral degree in educational psychology awarded to the first author. The first author received a bursary to complete this doctorate, under the UK government-funded Educational Psychology Funded Training (EPFT) Scheme.

\section{Declarations}

Conflict of Interest The authors declare no competing interests.

Open Access This article is licensed under a Creative Commons Attribution 4.0 International License, which permits use, sharing, adaptation, distribution and reproduction in any medium or format, as long as you give appropriate credit to the original author(s) and the source, provide a link to the Creative Commons licence, and indicate if changes were made. The images or other third party material in this article are included in the article's Creative Commons licence, unless indicated otherwise in a credit line to the material. If material is not included in the article's Creative Commons licence and your intended use is not permitted by statutory regulation or exceeds the permitted use, you will need to obtain permission directly from the copyright holder. To view a copy of this licence, visit http://creativecommons.org/licenses/by/4.0/. 


\section{References}

Ahmed, W., van der Werf, G., Kuyper, H., \& Minnaert, A. (2013). Emotions, self-regulated learning, and achievement in mathematics: A growth curve analysis. Journal of Educational Psychology, 105(1), 150161. https://doi.org/10.1037/a0030160.

Aschbacher, P. R., Koency, G., \& Schacter, J. (1995). Los Angeles Learning Center alternative assessments guidebook (resource paper no. 12). University of California, Los Angeles, National Center for Research on Evaluation, Standards, and Student Testing (CRESST).

Așık, G., \& Erktin, E. (2019). Metacognitive experiences: Mediating the relationship between metacognitive knowledge and problem solving. Egitim ve Bilim, 44(197), 85-103. https://doi.org/10.15390/EB.2019.7199.

Baker, L. (1989). Metacognition, comprehension monitoring, and the adult reader. Educational Psychology Review, 1(1), 3-38. https://doi.org/10.1007/BF01326548.

Bishara, S., \& Kaplan, S. (2018). The relationship of locus of control and metacognitive knowledge of math with math achievements. International Journal of Disability, Development and Education, 65(6), 631-648. https://doi.org/10.1080/1034912X.2018.1432033.

Borenstein, M., Hedges, L. V., Higgins, J. P. T., \& Rothstein, H. R. (2009). Introduction to metaanalysis. John Wiley \& Sons, Ltd.

Callan, G. L., \& Cleary, T. J. (2019). Examining cyclical phase relations and predictive influences of selfregulated learning processes on mathematics task performance. Metacognition and Learning, 14(1), 43-63. https://doi.org/10.1007/s11409-019-09191-x.

Callan, G. L., Marchant, G. J., Finch, W. H., \& German, R. L. (2016). Metacognition, strategies, achievement, and demographics: Relationships across countries. Kuram ve Uygulamada Egitim Bilimleri, 16(5), 14851502. https://doi.org/10.12738/estp.2016.5.0137.

Campbell, J. I. (2005). Handbook of mathematical cognition. Psychology Press.

Center, H. (2012). Battery math tests. Bar Ilan University.

Çetinkaya, P., \& Erktin, E. (2002). Assessment of metacognition and its relationship with reading comprehension, achievement, and aptitude. Boğaziçi Üniversitesi Ĕ̈itim Dergisi, 19(1), 1-11.

Chiu, M. M., Chow, B. W. Y., \& Mcbride-Chang, C. (2007). Universals and specifics in learning strategies: Explaining adolescent mathematics, science, and reading achievement across 34 countries. Learning and Individual Differences, 17(4), 344-365. https://doi.org/10.1016/j.lindif.2007.03.007.

Craig, K., Hale, D., Grainger, C., \& Stewart, M. E. (2020). Evaluating metacognitive self-reports: systematic reviews of the value of self-report in metacognitive research. Metacognition and Learning, 15(2), 155-213.

Crawford, C., \& Cribb, J. (2013). Reading and math skills at age 10 and earnings in later life: a brief analysis using the British cohort study. University of London.

Credé, M., \& Phillips, L. A. (2011). A meta-analytic review of the motivated strategies for learning questionnaire. Learning and Individual Differences, 21(4), 337-346. https://doi.org/10.1016/j.lindif.2011.03.002.

Critical Appraisal Skills Programme (2018). CASP cohort study checklist. CASP Checklists. https://casp-uk.net/ wp-content/uploads/2018/01/CASP-Cohort-Study-Checklist_2018.pdf.

Dennison, R. S., Krawchuk, C. M., Howard, B. C., \& Hill, L. 1996. The development of a children's self-report measure of metacognition. Annual meeting of the American Educational Research Association.

Dent, A. L., \& Koenka, A. C. (2016). The relation between self-regulated learning and academic achievement across childhood and adolescence: A meta-analysis. Educational Psychology Review, 28(3), 425-474. https://doi.org/10.1007/s10648-015-9320-8.

Department for Education (2014). Mathematics programmes of study: Key stage 4 National curriculum in England. https://www.gov.uk/government/publications/national-curriculum-in-england-mathematicsprogrammes-of-study.

Dermitzaki, I. (2005). Preliminary investigation of relations between young students' self-regulatory strategies and their metacognitive experiences. Psychological Reports, 97(3), 759-768. https://doi.org/10.2466/2Fpr0. 97.3.759-768.

Desoete, A., \& Roeyers, H. (2006). Metacognitive macroevaluations in mathematical problem solving. Learning and Instruction, 16(1), 12-25. https://doi.org/10.1016/j.learninstruc.2005.12.003.

Desoete, A., Roeyers, H., \& Buysse, A. (2001). Metacognition and mathematical problem solving in grade 3. Journal of Learning Disabilities, 34(5), 435-447. https://doi.org/10.1177/002221940103400505.

Dignath, C., \& Büttner, G. (2008). Components of fostering self-regulated learning among students: A metaanalysis on intervention studies at primary and secondary school level. Metacognition and Learning, 3(3), 231-264. https://doi.org/10.1007/s11409-008-9029-x.

Double, K. S., Birney, D. P., \& Walker, S. A. (2018). A meta-analysis and systematic review of reactivity to judgements of learning. Memory, 26(6), 741-750. https://doi.org/10.1080/09658211.2017.1404111.

Pearson Education. (2008). AIMSweb ${ }^{\circledR}$ benchmark and progress monitoring system for Grades $K-8$. 
Efklides, A. (2006). Metacognitive experiences: The missing link in the self-regulated learning process. Educational Psychology Review, 18(3), 287-291. https://doi.org/10.1007/s10648-006-9021-4.

Efklides, A. (2008). Metacognition: Defining its facets and levels of functioning in relation to self-regulation and co-regulation. European Psychologist, 13(4), 277-287. https://doi.org/10.1027/10169040.13.4.277.

Efklides, A., \& Vlachopoulos, S. P. (2012). Measurement of metacognitive knowledge of self, task, and strategies in mathematics. European Journal of Psychological Assessment, 28(3), 227-239. https://doi.org/ 10.1027/1015-5759/a000145.

Egger, M., Smith, G. D., Schneider, M., \& Minder, C. (1997). Bias in meta-analysis detected by a simple, graphical test. British Medical Journal, 315(7109), 629-634. https://doi.org/10.1136/bmj.315.7109.629.

Erktin, E. (2004). Teaching thinking for mathematics through the enhancement of metacognitive skills. Research in the Schools, 11(1), 3-13.

Fadlelmula, F. K., Cakiroglu, E., \& Sungur, S. (2015). Developing a structural model on the relationship among motivational beliefs, self-regulated learning strategies, and achievement in mathematics. International Journal of Science and Mathematics Education, 13(6), 1355-1375. https://doi.org/10.1007/s10763-0139499-4.

Fiacconi, C. M., Mitton, E. E., Laursen, S. J., \& Skinner, J. (2019). Isolating the contribution of perceptual fluency to judgments of learning (JOLs): Evidence for reactivity in measuring the influence of fluency. Journal of Experimental Psychology: Learning, Memory, and Cognition, 46(5), 926. https://doi.org/10. $1037 / x \operatorname{lm} 0000766$.

Fitzpatrick, C. (1994). Adolescent mathematical problem solving: The role of metacognition, strategies and beliefs (ED374969). ERIC. https://eric.ed.gov/?id=ED374969.

Flavell, J. H. (1979). Metacognition and cognitive monitoring: A new area of cognitive-developmental inquiry. American Psychologist, 34(10), 906-911. https://doi.org/10.1037/0003-066X.34.10.906.

Fusco, D. R. (1995). The role of strategy, effort and unknown attributions in a metacognitive model of mathematical problem solving [Doctoral dissertation, The City University of New York]. ProQuest Digital Collections. https://search.proquest.com/pqdtglobal/docview/304181779/19A59985BBA0439CPQ/ 1 ? accountid $=13963$.

Garrett, A. J., Mazzocco, M. M. M., \& Baker, L. (2006). Development of the metacognitive skills of prediction and evaluation in children with or without math disability. Learning Disabilities Research \& Practice, 21(2), 77-88. https://doi.org/10.1111/j.1540-5826.2006.00208.x.

Gascoine, L., Higgins, S., \& Wall, K. (2017). The assessment of metacognition in children aged 4-16 years: A systematic review. Review of Education, 5(1), 3-57. https://doi.org/10.1002/rev3.3077.

Hacker, D. J., Dunlosky, J., \& Graesser, A. C. (1998). Metacognition in educational theory and practice. Routledge.

Harris, M. M. (2015). The role of metacognition in a Montessori environment and the effects on academic achievement [Doctoral dissertation, Union University]. ProQuest Digital Collections. https://search.proquest. com/docview/1733667442?accountid=13963.

Hartwig, M. K., \& Dunlosky, J. (2014). The contribution of judgment scale to the unskilled-and-unaware phenomenon: How evaluating others can exaggerate over- (and under-) confidence. Memory \& Cognition, 42(1), 164-173. https://doi.org/10.3758/s13421-013-0351-4.

Hassan, N. M., \& Rahman, S. (2017). Problem solving skills, metacognitive awareness, and mathematics achievement: A mediation model. The New Educational Review, 49(3), 201-212.

Henfi, J. (1990). Redactiesommen. Ajodakt.

Higgins, J. P. T., Thompson, S. G., Deeks, J. J., \& Altman, D. G. (2003). Measuring inconsistency in metaanalyses. British Medical Journal, 327(7414), 557-560. https://doi.org/10.1136/bmj.327.7414.557.

Higham, P. A., \& Arnold, M. M. (2007). How many questions should I answer? Using bias profiles to estimate optimal bias and maximum score on formula-scored tests. European Journal of Cognitive Psychology, 19(45), 718-742. https://doi.org/10.1080/09541440701326121.

Hodgen, J. \& Pepper, D. (2010). An international comparison of upper secondary mathematics education. Nuffield Foundation 2010. https://wwwnuffieldfoundation.org.

Hong, E., \& Peng, Y. (2004). Test-taking strategies questionnaire. Unpublished document.

Ichihara, M., \& Arai, K. (2006). Moderator effects of meta-cognition: A test in math of a motivational model. Japanese Journal of Educational Psychology, 54(2), 199-210.

Jackson, D., White, I. R., \& Riley, R. D. (2012). Quantifying the impact of between-study heterogeneity in multivariate meta-analyses. Statistics in Medicine, 31(29), 3805-3820. https://doi.org/10.1002/sim.5453.

Janes, J. L., Rivers, M. L., \& Dunlosky, J. (2018). The influence of making judgments of learning on memory performance: Positive, negative, or both? Psychonomic Bulletin \& Review, 25(6), 2356-2364. https://oi. org/10.3758/s13423-018-1463-4. 
Jordano, M. L., \& Touron, D. R. (2018). How often are thoughts metacognitive? Findings from research on selfregulated learning, think-aloud protocols, and mind-wandering. Psychonomic Bulletin \& Review, 25(4), 1269-1286. https://doi.org/10.3758/s13423-018-1490-1.

Kramarski, B., Rich, I., Mevarech, Z., \& Libereman, A. (2005). The effect of metacognitive processes on achievement motivation and mathematical thinking among students in middle schools. Bar Ilan University.

Kruger, J., \& Dunning, D. (1999). Unskilled and unaware of it: How difficulties in recognizing one's own incompetence lead to inflated self-assessments. Journal of Personality and Social Psychology, 77(6), 11211134. https://doi.org/10.1037/0022-3514.77.6.1121.

Lucangeli, D., \& Cornoldi, D. (1997). Mathematics and metacognition: What is the nature of the relationship? Mathematical Cognition, 3(2), 121-139. https://doi.org/10.1080/135467997387443.

Maras, K., Gamble, T., \& Brosnan, M. (2019). Supporting metacognitive monitoring in mathematics learning for young people with autism spectrum disorder: A classroom-based study. Autism, 23(1), 60-70. https://doi. org/10.1177/1362361317722028.

Martín, E., Martínez-Arias, R., Marchesi, A., \& Pérez, E. M. (2008). Variables that predict academic achievement in the Spanish compulsory secondary educational system: A longitudinal, multi-level analysis. The Spanish Journal of Psychology, 11(2), 400-413. https://doi.org/10.1017/ S113874160000442X.

Martin, R., Hodgson, H., Maloney, A. \& Rayner, I. (2014). Pro bono economics report for national numeracy: Cost of outcomes associated with low levels of adult numeracy in the UK. National Numeracy. https://www. probonoeconomics.com/sites/default/files/files/PBE\%20National\%20Numeracy\%20costs\%20report\% 2011Mar.pdf.

Mathematics Diagnostic Testing Project. (2006). The MDTP assessment system. The California State University/ University of California Mathematics Diagnostic Testing Project https://mdtp.ucsd.edu/assessments/index. html.

Mayer, R. E. (1998). Cognitive, metacognitive, and motivational aspects of problem solving. Instructional Science, 26(1-2), 49-63. https://doi.org/10.1023/A:1003088013286.

Meltzer, L. J., Levine, M. D., Karniski, W., Palfrey, J. S., \& Clarke, S. (1984). An analysis of the learning styles of adolescent delinquents. Journal of Learning Disabilities, 17(10), 600-608. https://doi.org/10.1177/ 002221948401701006.

Metcalfe, J., \& Finn, B. (2008). Evidence that judgments of learning are causally related to study choice. Psychonomic Bulletin and Review, 15(1), 174-179. https://doi.org/10.3758/PBR.15.1.174.

Missouri Department of Elementary and Secondary Education (1990). Mastery and achievement tests: Guide to score, interpretation and Use. Jefferson City.

Moher, D., Shamseer, L., Clarke, M., Ghersi, D., Liberati, A., Petticrew, M., et al. (2015). Preferred reporting items for systematic review and meta-analysis protocols (PRISMA-P) 2015 statement. Revista Espanola de Nutricion Humana y Dietetica, 20(2), 148-160. https://doi.org/10.1186/2046-4053-4-1.

Mokos, E., \& Kafoussi, S. (2013). Elementary students' spontaneous metacognitive functions in different types of mathematical problems. Journal of Research in Mathematics Education, 2(2), 242-267. https://doi.org/ 10.4471/redimat.2013.29.

Montague, M., \& Bos, C. S. (1990). Cognitive and metacognitive characteristics of eighth grade students' mathematical problem solving. Learning and Individual Differences, 2(3), 371-388. https://doi.org/10.1016/ 1041-6080(90)90012-6.

Moran, T. P. (2016). Anxiety and working memory capacity: A meta-analysis and narrative review. Psychological Bulletin, 142(8), 831-864. https://doi.org/10.1037/bul0000051.

Moreno, A. (2002). The assessment of metacognitive skills. In A. Marchesi \& E. Martín (Eds.), Secondary education assessment (pp. 119-136) Editorial SM.

Mullis, I. V. S., Martin, M. O., Foy, P., Kelly, D. L., \& Fishbein, B. (2020). TIMMS 2019 International results in maths and science. International Association for the Evaluation of Educational Achievement. Boston College https://timssandpirls.bc.edu/timss2019/.

Murayama, K., Pekrun, R., Lichtenfeld, S., \& Vom Hofe, R. (2013). Predicting long-term growth in students' mathematics achievement: The unique contributions of motivation and cognitive strategies. Child Development, 84(4), 1475-1490. https://doi.org/10.1111/cdev.12036.

Myers, S. J., Rhodes, M. G., \& Hausman, H. E. (2020). Judgments of learning (JOLs) selectively improve memory depending on the type of test. Memory \& Cognition, 48(5), 1-14. https://doi.org/10.3758/s13421020-01025-5.

Nelson, T. O., \& Narens, L. (1990). Metamemory: A theoretical framework and new findings. In G. H. Bower (Ed.), The psychology of learning and motivation (pp. 125-141). Academic. https://doi.org/10.1016/S00797421(08)60053-5.

Ning, H. K. (2016). Examining heterogeneity in student metacognition: A factor mixture analysis. Learning and Individual Differences, 49, 373-377. https://doi.org/10.1016/j.lindif.2016.06.004. 
National Numeracy. (2020). What is numeracy? National Numeracy. https://www.nationalnumeracy.org.uk/ what-numeracy.

Ofqual (2019). An infographic: GCSEs in 2019. Key stage 3 and 4 exam marking, qualifications and results. https://assets.publishing.service.gov.uk/government/uploads/system/uploads/attachment_data/file/826795/ GCSE_infographic_17____.pdf.

Ohtani, K., \& Hisasaka, T. (2018). Beyond intelligence: A meta-analytic review of the relationship among metacognition, intelligence, and academic performance. Metacognition and Learning, 13(2), 179-212. https://doi.org/10.1007/s11409-018-9183-8.

O'Neil, H. F., \& Abedi, J. (1996). Reliability and validity of a state metacognitive inventory: Potential for alternative assessment. The Journal of Educational Research, 89(4), 234-245. https://doi.org/10.1080/ 00220671.1996 .9941208 .

Ouzzani, M., Hammady, H., Fedorowicz, Z., \& Elmagarmid, A. (2016). Rayyan - a web and mobile app for systematic reviews. Systematic Reviews, 5(1), 1-10. https://doi.org/10.1186/s13643-016-0384-4.

Özcan, Z. Ç. (2016). The relationship between mathematical problem-solving skills and self-regulated learning through homework behaviours, motivation, and metacognition. International Journal of Mathematical Education in Science and Technology, 47(3), 408-420. https://doi.org/10.1080/0020739X.2015.1080313.

Özcan, Z. Ç., \& Eren Gümüș, A. (2019). A modeling study to explain mathematical problem-solving performance through metacognition, self-efficacy, motivation, and anxiety. Australian Journal of Education, 63(1), 116-134. https://doi.org/10.1177/0004944119840073.

Özsoy, G. (2005). The relationship between problem solving skills and mathematical achievement. Gazi University Journal of Education, 25(3), 179-190.

Özsoy, G. (2011). An investigation of the relationship between metacognition and mathematics achievement. Asia Pacific Education Review, 12(2), 227-235. https://doi.org/10.1007/s12564-010-9129-6.

Panaoura, A., \& Philippou, G. (2003). The construct validity of an inventory for the measurement of young pupils' metacognitive abilities in mathematics (ED501054). ERIC. https://eric.ed.gov/?id=ED501054.

Parsons, S (2002). Basic skills and crime. Basic Skills Agency. https://discovery.ucl.ac.uk/id/eprint/1566250/.

Paulus, N., Tsalas, J., Proust, B., \& Sodian, B. (2014). Metacognitive monitoring of oneself and others: Developmental changes during childhood and adolescence. Journal of Experimental Child Psychology, 122, 153-165. https://doi.org/10.1016/j.jecp.2013.12.011.

Peng, Y., Hong, E., \& Mason, E. (2014). Motivational and cognitive test-taking strategies and their influence on test performance in mathematics. Educational Research and Evaluation, 20(5), 366-385. https://doi.org/10. 1080/13803611.2014.966115.

Perry, J., Lundie, D., \& Golder, G. (2019). Metacognition in schools: What does the literature suggest about the effectiveness of teaching metacognition in schools? Educational Review, 7(4), 483-500. https://doi.org/10. 1080/00131911.2018.1441127.

Pintrich, P. R. (1991). A manual for the use of the motivated strategies for learning questionnaire (MSLQ). (ED338122). ERIC. https://eric.ed.gov/?id=ED338122.

Price, G., \& Ansari, D. (2013). Dyscalculia: Characteristics, causes, and treatments. Numeracy, 6(1), 1-16. https://doi.org/10.5038/1936-4660.6.1.2.

Pustejovsky, JE, \& Tipton, E. (2021). Meta-analysis with robust variance estimation: Expanding the range of working models. OSF, https://osf.io/mq9hj/.

Richardson, M., Abraham, C., \& Bond, R. (2012). Psychological correlates of university students' academic performance: A systematic review and meta-analysis. Psychological Bulletin, 138(2), 353-387.

Saraç, S., \& Karakelle, S. (2012). On-line and off-line assessment of metacognition. International Electronic Journal of Elementary Education, 4(2), 301-315.

Sato, J., \& Arai, K. (1998). The relation between the use of learning strategies, learning goals and causal attributions. Tsukuba Psychological Research, 20, 115-124.

Schneider, W. (2008). The development of metacognitive knowledge in children and adolescents: Major trends and implications for education. Mind, Brain and Education, 2(3), 114-121. https://doi.org/10.1111/j.1751228X.2008.00041.x.

Schraw, G., \& Dennison, R. S. (1994). Assessing metacognitive awareness. Contemporary Educational Psychology, 19(4), 460-475. https://doi.org/10.1006/ceps.1994.1033.

Schraw, G., Olafson, L., Weibel, M., \& Sewing, D. (2012). Metacognitive knowledge and field-based science learning in an outdoor environmental education program. In A. Zohar \& Y. Dori (Eds.), Metacognition in science education: Trends in current research (pp. 57-77). Springer. https://doi.org/10.1007/978-94-0072132-6 4.

Siddaway, A. P., Wood, A. M., \& Hedges, L. V. (2019). How to do a systematic review: A best practice guide for conducting and reporting narrative reviews, meta-analyses, and meta-syntheses. Annual Review of Psychology, 70(1), 747-770. https://doi.org/10.1146/annurev-psych-010418. 
Sink, C. A., Barnett, J. E., \& Hixon, J. E. 1991. Self-regulated learning and academic performance in middle school children. Annual meeting of the American Educational Research Association.

Son, L. K., \& Metcalfe, J. (2000). Metacognitive and control strategies in study-time allocation. Journal of Experimental Psychology: Learning, Memory, and Cognition, 26(1), 204-221. https://doi.org/10.1037/ 0278-7393.26.1.204.

Sperling, R. A., Howard, B. C., Miller, L. A., \& Murphy, C. (2002). Measures of children's knowledge and regulation of cognition. Contemporary Educational Psychology, 27(1), 51-79. https://doi.org/10.1006/ceps. 2001.1091.

Sperling, R. A., Howard, B. C., Staley, R., \& DuBois, N. (2004). Metacognition and self-regulated learning constructs. International Journal of Phytoremediation, 21(1), 117-139. https://doi.org/10.1076/edre.10.2. 117.27905.

Steinmayr, R., Ziegler, M., \& Träuble, B. (2010). Do intelligence and sustained attention interact in predicting academic achievement? Learning and Individual Differences, 20(1), 14-18. https://doi.org/10.1016/j.lindif. 2009.10.009.

Tekin, E., \& Rodiger, H. L. (2020). Reactivity of judgments of learning in a levels-of-processing paradigm. Zeitschrift Für Psychologie, 228(4), 278-290. https://doi.org/10.1027/2151-2604/a000425.

Tian, Y., Fang, Y., \& Li, J. (2018). The effect of metacognitive knowledge on mathematics performance in selfregulated learning framework-multiple mediation of self-efficacy and motivation. Frontiers in Psychology, 9, 2518. https://doi.org/10.3389/fpsyg.2018.02518.

Tipton, E. (2015). Small sample adjustments for robust variance estimation with meta-regression. Psychological Methods, 20(3), 375-393. https://doi.org/10.1037/met0000011.

Tobias, S., Everson, H. T., \& Laitusis, V. (1999). Towards a performance-based measure of metacognitive knowledge monitoring: Relationships with self-reports and behaviour ratings. (ED432590). ERIC. https:// eric.ed.gov/?id=ED432590.

van der Stel, M., \& Veenman, M. V. J. (2014). Metacognitive skills and intellectual ability of young adolescents: A longitudinal study from a developmental perspective. European Journal of Psychology of Education, 29(1), 117-137. https://doi.org/10.1007/s10212-013-0190-5.

van der Stel, M., Veenman, M. V. J., Deelen, K., \& Haenen, J. (2010). The increasing role of metacognitive skills in math: A cross-sectional study from a developmental perspective. International Journal on Mathematics Education, 42(2), 219-229. https://doi.org/10.1007/s11858-009-0224-2.

van der Walt, M. S., Maree, J. G., \& Ellis, S. M. (2008). Metacognition in the learning of mathematics in the senior phase: Some implications for the curriculum. International Journal of Adolescence and Youth, 14(3), 205-235. https://doi.org/10.1080/02673843.2008.9748004.

Veenman, M. V., \& Spaans, M. A. (2005). Relation between intellectual and metacognitive skills: Age and task differences. Learning and Individual Differences, 15(2), 159-176. https://doi.org/10.1016/j.lindif.2004.12. 001.

Veenman, M. V. J., \& van Cleef, D. (2019). Measuring metacognitive skills for mathematics: Students' selfreports versus on-line assessment methods. Mathematics Education, 51(4), 691-701. https://doi.org/10. 1007/s11858-018-1006-5.

Veenman, M. V. J., Kerseboom, L., \& Imthorn, C. (2000). Test anxiety and metacognitive skillfulness: Availability versus production deficiencies. Anxiety, Stress and Coping, 13(4), 391-412. https://doi.org/ 10.1080/10615800008248343.

Veenman, M. V. J., Kok, R., \& Blöte, A. W. (2005). The relation between intellectual and metacognitive skills in early adolescence. Instructional Science, 33(3), 193-211. https://doi.org/10.1007/s11251-0042274-8.

Veenman, M. V. J., van Hout-Wolters, B. H. A. M., \& Afflerbach, P. (2006). Metacognition and learning: Conceptual and methodological considerations. Metacognition and Learning, 1(1), 3-14. https://doi.org/10. 1007/s11409-006-6893-0.

Verschaffel, L., van Dooren, W., Greer, B., \& Mukhopadhyay, S. (2010). Reconceptualising word problems as exercises in mathematical modelling. Journal Fur Mathematik-Didaktik, 31(1), 9-29. https://doi.org/10. 1007/s13138-010-0007-x.

Viechtbauer, W. (2010). Conducting meta-analyses in $\mathrm{R}$ with the metafor package. Journal of statistical software, 36(3), 1-48 v36i03.pdf.

Vuorre, M., \& Metcalfe, J. (2021). Measures of relative metacognitive accuracy are confounded with task performance in tasks that permit guessing. Metacognition and Learning. Advance online publication. https:// doi.org/10.1007/s1 1409-020-09257-1-1.

Walker, E. (2013). Understanding the role of metacognition and working memory in math achievement [Doctoral dissertation, University of Southampton]. University of Southampton Digital Collections https:/eprints.soton.ac.uk/358501/. 
Wilkinson, G. S., \& Robertson, G. J. (2006). Wide range achievement test (WRAT4). Psychological Assessment Resources.

Wolf, A. (2011). Review of vocational education- The Wolf report. Department for Education. http://www. educationengland.org.uk/documents/pdfs/2011-wolf-report-vocational.pdf

Wolters, C. A., Pintrich, P. R., \& Karabenick, S. A. (2006). Assessing academic self-regulated learning. In K. A. Moore \& L. H. Lippman (Eds.), What do children need to flourish? (pp. 251-270). Springer. https://doi.org/ 10.1007/0-387-23823-9 16 .

Yap, E. G. (1993). A structural model of self-regulated learning in math achievement [Doctoral dissertation, University of Southern California]. ProQuest Digital Collections. https://search.proquest.com/docview/ 1627936537 ?accountid $=13963$

Young, A. E., \& Worrell, F. C. (2018). Comparing metacognition assessments of mathematics in academically talented students. Gifted Child Quarterly, 62(3), 259-275. https://doi.org/10.1177/ 0016986218755915.

Zimmerman, B. J. (1989). A social cognitive view of self-regulated academic learning. Journal of Educational Psychology, 81(3), 329-339. https://doi.org/10.1037/0022-0663.81.3.329.

Publisher's Note Springer Nature remains neutral with regard to jurisdictional claims in published maps and institutional affiliations.

\section{Affiliations}

\section{Gemma Muncer $^{1}$ • Philip A. Higham ${ }^{2}$ - Corentin J. Gosling ${ }^{3,4} \cdot$ Samuele Cortese ${ }^{5,6,7,8,9}$ • Henry Wood-Downie ${ }^{5,10}$ - Julie A. Hadwin ${ }^{11}$}

1 BCP Educational Psychology Service, Dolphin Centre, Poole BH15 1SA, UK

2 Centre for Perception and Cognition, School of Psychology, University of Southampton, Highfield, Southampton SO17 1BJ, UK

3 DysCo Lab, Department of Psychology, Paris Nanterre University, F-92100 Nanterre, France

4 Université de Paris, Laboratoire de Psychopathologie et Processus de Santé, F-92100 Boulogne Billancourt, France

5 Centre for Innovation in Mental Health-Developmental Lab, School of Psychology, University of Southampton, Highfield, Southampton SO17 1BJ, UK

6 Clinical and Experimental Sciences (CNS and Psychiatry), Faculty of Medicine, University of Southampton, Southampton, UK

7 Solent NHS Trust, Southampton, UK

8 Hassenfeld Children's Hospital at NYU Langone, New York University Child Study Center, New York City, New York, USA

9 Division of Psychiatry and Applied Psychology, School of Medicine, University of Nottingham, Nottingham, UK

10 West Sussex Educational Psychology Service, 3rd Floor County Hall North, Chart Way, Horsham RH12 1XH, UK

11 Childhood Research Forum and Centre for Education and Policy Analysis, School of Education, Liverpool Hope University, Hope Park, Liverpool L16 9JD, UK 